\title{
Low-Latitude Aurorae and Storm Time Current Systems
}

\author{
B. A. Tinsley, R. Rohrbaugh, and H. Rassoul \\ The University of Texas at Dallas, Richardson \\ Y. SAHAi AND N. R. TeiXeIRA \\ Instituto de Pesquısas Espaciais, São Jose des Campos, São Paulo, Brazil \\ D. SLATER
}

Battelle Pacific Northwest Laboratory, Richland, Washington

\begin{abstract}
An analysis is made of the vibrational development shown in $\mathrm{N}_{2}^{+} 1 \mathrm{~N}$ (first negative) emissions in low-latitude aurorae during the last half century. The data imply collisional excilation by energetic heavy particles (oxygen, helium, or hydrogen ions or neutrals) of velocity of the order of $10^{7} \mathrm{~cm} \mathrm{~s}^{-1}$, and there may be additional pumping in some cases due to solar photons and low-energy electrons. When lowenergy electrons are present as large fluxes, they produce bright red (O I $6300 \AA$ ) emission, with weaker emission from N I $5200 \AA$ and other features of excitation potential only a few electron volts. From about $40^{\circ}$ dip latitude to the auroral zone the decrease of $\mathrm{N}_{2}^{+}{ }^{+} \mathrm{N}$ vibrational development with increasing latitude is consistent with satellite observations of the increase with increasing latitude of the mean energy of precipitating $\mathrm{O}^{+}$fluxes and the increasing fraction of $\mathrm{H}^{+}$in the ion precipitation. From the equator to about $40^{\circ}$ dip latitude the intensity and the latitudinal gradients of the emissions are consistent with energetic neutral precipitation as the primary source. The intensity variations of lowlatitude displays show large-amplitude changes on a time scale of 0.1 hour, which are closely related to the magnetic signatures of the storm time current system. The brightest emissions occur when $|D s t|$ is large and specifically when positive $H$ excursions take place, with first positive then negative $D$ excursions, as recorded on magnetograms from nearby observatories. The positive $\Delta H$ at low latitudes is accompanied by the negative $\Delta H$ of large substorms as recorded at higher latitude observatories. The 0.1 -hour time scale of these fluctuations implies that the ring current is incompletely shielded, allowing ionospheric currents and the injection of the ring current to unusually low latitudes.
\end{abstract}

\section{INTRODUCTION}

Aurorae which are seen at low latitudes at the time of large magnetic storms have spectral characteristics which are quite distinct from the "ordinary" aurora excited by keV electrons which are the most frequently seen in the auroral zone. Such aurorae have been recorded visually for many centuries in southern Europe and the United States, Japan, India, Singapore, Cuba, and Hawaii, and reviews of such observations have been given in eight articles by Loomis [1859-1861], Barbier [1949], Seaton [1956], Chapman [1957a, b], and Chamberlain [1961]. Recent observations of the spectral characteristics of such aurorae from McDonald Observatory, southwest Texas, have been discussed by Tinsley et al. [1984]. The lowlatitude aurorae are characterized by (1) $\mathrm{N}_{2}+1 \mathrm{~N}$ emission with high vibrational development, where $1 \mathrm{~N}$ means first negative, (2) a high $(>10)$ ratio of red $(6300 \AA)$ to green $(5577$ $\AA)$ atomic oxygen lines, and (3) prominence of atomic/ionic lines $\mathrm{O}, \mathrm{O}^{+}, \mathrm{N}$, and $\mathrm{N}^{+}$as compared to molecular bands.

In this paper we study the spectral characteristics of lowlatitude aurorae recorded during the last 60 years, and especially the vibrational populations for the $\mathrm{N}_{2}{ }^{+} B^{2} \Sigma_{u}{ }^{+}$state which give rise to the $\mathrm{N}_{2}{ }^{+} 1 \mathrm{~N}$ bands, with a view to evaluating contributions from several excitation mechanisms. We also examine latitude variations of vibrational development and emission rate and compare the time variation of some low-latitude displays with the magnetic signatures from

\section{Copyright 1986 by the American Geophysical Union.}

Paper number 6A8467.

0148-0227/86/006A-8467\$05.00 nearby observatories with a view to identifying characteristics of the associated storm time current systems.

\section{Excitation Mechanisms for Low-Latitude Aurorae}

There are three mechanisms which can produce the high vibrational excitation of $\mathrm{N}_{2}+1 \mathrm{~N}$. The first is precipitation of heavy particles (ions or neutral atoms of $\mathrm{H}, \mathrm{He}, \mathrm{O}$ ) at velocities of $<10^{8} \mathrm{~cm} \mathrm{~s}^{-1}$. This mechanism was the first to be proposed, resulting from a comparison of an auroral spectrum observed near London with the spectrum excited by cathode rays in air [Rayleigh, 1922]. It was supported by measurements of the spectra of the impact of heavy particles in air [Fan, 1956] and in nitrogen [Carleton, 1957].

The second mechanism is resonant scattering of sunlight on $\mathrm{N}_{2}{ }^{+} X$ ions. Bates [1949] suggested this as additional to heavy particle impact in low-latitude aurorae. Support for this interpretation was the realization that a number of spectra of low-latitude aurorae were obtained with exposures that included periods when the upper atmosphere being observed was sunlit. The aurora reported by Rayleigh [1922] can be shown to have been sunlit.

The third mechanism is collision of large numbers of lowenergy electrons with $\mathrm{N}_{2}{ }^{+} X$ ions [Degen, 1981]. Support for this interpretation is the strong $6300-\AA$ emission seen in many low-latitude aurorae, implying large fluxes of electrons of energy of $\sim 1 \mathrm{eV}$.

In great low-latitude aurorae the most prominent feature usually observed is this $6300-\AA$ line of oxygen, which is from metastable $O\left({ }^{1} D\right)$ with an excitation potential of $1.96 \mathrm{eV}$. Usually, the second most prominent feature is the $\mathrm{N}_{2}{ }^{+} 1 \mathrm{~N}$ emission. From a study of low-latitude aurorae at $\mathrm{McDonald} \mathrm{Ob}$ - 
TABLE 1. Spectroscopy/Photometry of Low-Latitude Aurorae

\begin{tabular}{|c|c|c|}
\hline Event & Location & Reference \\
\hline May 13-14, 1921 & Terling, England & Rayleigh $[1922]$ \\
\hline June 7,1928 & Flagstaff, Ariz. & Slipher and Sommer [1929] \\
\hline May 29, 1932 & Flagstaff, Ariz. & Slipher [1933] \\
\hline \multirow[t]{2}{*}{ Jan. $25-26,1938$} & Lyon, France & Dufay and Gauzit [1938] \\
\hline & Arosa, Switzerland & Goltz [1938] \\
\hline March 29, 1940 & Arosa, Switzerland & Gotz and Brunner-Hogger [1940] \\
\hline March 1, 1941 & Lyon, France & Dufy et. al. $[1941]$ \\
\hline \multirow{3}{*}{ Sept. 18-19, 1941} & Arosa, Switzerland & Gotz $[1941]$ \\
\hline & Haute Provence, France & Dufay and Tcheng [1942] \\
\hline & Arosa, Switzerland & Gotz and Schmid [1942] \\
\hline \multirow[t]{2}{*}{ April 17-18, 1947} & Arosa, Switzerland & Gotz [1947] \\
\hline & Haute Provence, France & Barbier [1947] \\
\hline Jan. 21, 1957 & Haute Provence, France & Dufay and Moreau [1957] \\
\hline Sept. 29-30, 1957 & Haute Provence, France & Dufay $[1957]$ \\
\hline \multirow[t]{4}{*}{ Feb. 11,1958} & Sacramento Park, N. M. & Manrung and Pettit [1959] \\
\hline & Niigata, Japan & Hikosaka $[1958]$ \\
\hline & Memambetsu Observatory, Japan & Huruhata $[1958]$ \\
\hline & Abastumani, Armenia, U.S.S.R. & Fishkova and Markova [1958] \\
\hline July 8, 1958 & Sydney, Australia & Duncan [1959] \\
\hline 1959-1961 & Niigata, Japan & Hirao et al. [1965] \\
\hline $1960-1962$ & Christchurch, New Zealand & Tinsley $[1963]$ \\
\hline Jan. 7, 1967 & Socorro, N. M. & Tinsley $[1968]$ \\
\hline 1972 & orbit, equatorial & Levasseur and Blamont [1973] \\
\hline $1972-1973$ & orbit, equatorial & Meier and Weller [1975] \\
\hline 1972 & orbit, low latitude & Shepherd et al. [1976] \\
\hline 1975-1976 & Adelaide, Australia & Chamberlain and Jacka [1979] \\
\hline July, 1975 & orbit, equatorial & Paresce [1979] \\
\hline May 2-3, 1976 & Arecibo, Puerto Rico & Burnside et al. $[1980]$ \\
\hline 1976-1977 & Huancayo, Peru & Tinsley $[1979]$ \\
\hline April-May, 1978 & Arecibo, Puerto Rico & Meriwether and Walker [1980] \\
\hline Sept. 29,1978 & Arecibo, Puerto Rico & Tinsley and Burnside [1981] \\
\hline $1981-1982$ & Hawaii, Brazil & Tinsley et al. [1982] \\
\hline 1981-1982 & Texas, Hawaii, Brazil & Rohrbaugh et al. [1983] \\
\hline Sept. 21-22, 1982 & Logan, Utah & Torr and Torr [1984] \\
\hline June 13,1983 & Texas & Tinsley et al. [1984] \\
\hline
\end{tabular}

servatory, Texas, we have found that the ratio of the intensity of the $6300-\AA$ emission, $I(6300)$, to the intensity of the $\mathrm{N}_{2}+1$ $\mathrm{N}$ band system, $I\left(\mathrm{~N}_{2}{ }^{+} 1 \mathrm{~N}\right.$ sys. $)$ is quite variable, sometimes being much greater than unity and sometimes being much less [Tinsley et al., 1984]. We have suggested that two populations of exciting particles are present, the first being energetic neutrals or ions, with energies of a few keV for oxygen, hydrogen, and/or helium, and the second being low-energy or hot electrons, of energy $k T \sim 1 \mathrm{eV}$, such that the Maxwellian highenergy tail will excite much $6300-\AA$ emission with excitation potential of $1.96 \mathrm{eV}$, but little 5577 emission with excitation potential of $4.17 \mathrm{eV}$. The hot electrons would also excite $5200-\AA$ emission from $\mathrm{N}\left({ }^{2} D\right)$ at $2.37 \mathrm{eV}$ and a small amount of $10,400-\AA$ emission from $\mathrm{N}\left({ }^{2} P\right)$ at $3.56 \mathrm{eV}$.

Thus if $I\left(\mathrm{~N}_{2}{ }^{+} 1 \mathrm{~N}\right.$ sys.) $\gg I([\mathrm{O} \mathrm{I}] 6300 \AA)$, we infer predominantly energetic neutral atom/ion excitation and describe the event as a neutral atom/ion aurora, or heavy particle aurora, and if $I([\mathrm{O} \mathrm{I}] 6300 \AA) \gg I\left(\mathrm{~N}_{2}{ }^{+} 1 \mathrm{~N}\right.$ sys.), we infer predominantly low-energy electron excitation and describe the event as a low-energy electron aurora.

In some cases, $\mathrm{H}$ Balmer $\beta$ is present and covaries with the $\mathrm{N}_{2}{ }^{+} 1 \mathrm{~N}$ emission, and at other times it appears to be absent.

In both types of aurorae the $\mathrm{N}_{2}{ }^{+} 1 \mathrm{~N}$ emission which is present has high vibrational development. The obvious source of precipitating energetic neutral atoms or ions to excite the $\mathrm{N}_{2}+1 \mathrm{~N}$ emission is the trapped ions of the ring current, which carry a quantity of energy comparable to that dumped in the auroral zones during a magnetic storm. We now know that these species are $\mathrm{O}^{+}, \mathrm{H}^{+}$, and $\mathrm{He}^{+}$, which are sometimes precipitated directly at middle and high latitudes but usually precipitated at low and equatorial latitudes as $\mathrm{O}, \mathrm{H}$, and $\mathrm{He}$ due to the charge exchange of the trapped ions with exospheric neutral hydrogen. The ionic content of the ring current has been reviewed by Williams [1981], and measurements of precipitating $\mathrm{O}^{+}, \mathrm{H}^{+}$, and $\mathrm{He}^{+}$have been made by Sharp et al. $[1976 a, b]$. Neutral atom precipitation has been reviewed by Tinsley [1981].

The source of the low-energy electrons for low-latitude aurorae would appear to be different from the source of such electrons for stable auroral red (SAR) arcs [Rees and Roble, 1975; Kozyra et al., 1982], where the hot electrons at thermospheric altitudes are thought to result from advection or heat conduction down from a region above $1000-\mathrm{km}$ altitude, possibly from a source involving interaction between the ring current and thermal plasma. The SAR arcs are narrow in latitude, of long east-west extent (perhaps girdling the earth), of many hours duration, and found in relatively quiet (recovery phase) conditions.

The low-latitude auroral $6300-\AA$ emission, by contrast, is of relatively short duration (tens of minutes), during active (main phase) magnetic conditions, and as we will show, the intensity is closely related to local magnetic perturbations. A possible source of thermospheric hot electrons would be storm time currents passing through the thermosphere. Some contribution to $6300-\AA$ emission may be due to collisional excitation by precipitating ions/neutrals and their secondaries [Torr et al., 1974].

Table 1 lists published spectroscopic and photometric 
TABLE 2. Spectral Features Observed in Low-Latitude Aurorae

\begin{tabular}{|c|c|c|c|}
\hline Feature & $\lambda, \AA$ & $\begin{array}{c}\text { Excitation } \\
\text { Potential, } \\
\text { eV }\end{array}$ & First Reported \\
\hline \multicolumn{4}{|l|}{ Atomic lines } \\
\hline$[\mathrm{N} \mathrm{I}]^{2} D^{0}-{ }^{4} S^{0}$ & $5198-5201$ & 2.37 & Slipher and Sommer [1929] \\
\hline$[\mathrm{N}]^{2} P^{0}-^{2} D^{0}$ & $10,395-10,404$ & 3.56 & Dufay [1957] \\
\hline$[\mathrm{O} I]^{1} D-{ }^{3} P$ & 6300 & 1.96 & Rayleigh $[1922]$ \\
\hline$\left[\begin{array}{lll}O & 1\end{array}\right]^{1} S{ }^{1} D$ & 5577 & 4.17 & Rayleigh [1922] \\
\hline$[\mathrm{N} I I]^{1} S-{ }^{1} D$ & 5755 & 18.57 & Dufay $[1957]$ \\
\hline$[\mathrm{O} I \mathrm{II}]^{2} P-^{2} D$ & $7319-7330$ & 18.61 & Dufay [1957] \\
\hline$N 13^{4} P^{0}-3^{4} P$ & 8216 & 11.79 & Dufay $[1957]$ \\
\hline N I $3^{4} D^{0}-3^{4} P$ & 8680 & 11.71 & Dufay [1957] \\
\hline O I $5^{3} D^{0}-3^{3} P$ & 5958 & 12.97 & Dufay [1957] \\
\hline O I $4^{5} D^{0}-3^{5} P$ & 6157 & 12.70 & Dufay $[1957]$ \\
\hline O I $3^{5} P-3^{5} S^{0}$ & 7774 & 10.69 & Dufay [1957] \\
\hline O I $3^{3} P-3^{3} S^{0}$ & 8446 & 10.94 & Dufay [1957] \\
\hline $\mathrm{OI} 3^{5} D-3^{5} P$ & 9266 & 12.05 & Dufay $[1957]$ \\
\hline $\mathrm{O}$ II $3^{2} D^{0}-3^{2} P$ & 4416 & 26.14 & Tinsley $[1979]$ \\
\hline H Ba $\alpha 3^{2} D-2^{2} P^{0}$ & 6563 & 12.04 & Levasseur and Blamont [1973] \\
\hline $\mathrm{H} \mathrm{Ba} \beta 4^{2} D-2^{2} P^{0}$ & 4861 & 12.69 & Tinsley [1979] \\
\hline He I $2^{3} P^{0}-2^{3} S$ & 10,830 & $\begin{array}{c}18.83 \\
\text { (twilight) }\end{array}$ & Tinsley $[1968]$ \\
\hline He II Ly $\alpha 2^{2} D-1^{2} P^{0}$ & & 40.76 & Meier and Weller [1975] \\
\hline He II Pa $\alpha 4^{2} D-3^{2} P$ & 4686 & & Tinsley $[1979]$ \\
\hline \multicolumn{4}{|l|}{ Molecular Bands } \\
\hline \multirow[t]{2}{*}{$\mathrm{N}_{2}^{+} 1 \mathrm{~N}$} & & 15.5 & Rayleigh [1922] \\
\hline & & $\begin{array}{c}\text { (twillight) } \\
18.7 \\
\text { (night) }\end{array}$ & Barbier [1947] \\
\hline $\mathrm{N}_{2}^{+}$Meinel & & 16.7 & Dufay and Moreau [1957] \\
\hline $\mathrm{N}_{2} 1 \mathrm{P}$ ? (weak) & & 7.3 & Dufay $[1957]$ \\
\hline
\end{tabular}

measurements on individual low-latitude aurorae, starting with Rayleigh's aurora of 1921. Table 2 lists spectral features established in low-latitude aurorae.

The incoming $\mathrm{keV}$ neutrals and ions will lose most of their energy in the height range $230-300 \mathrm{~km}$ [Torr and Torr, 1979], and the relative importance of atomic lines of $\mathrm{O}, \mathrm{N}, \mathrm{O}^{+}$, and $\mathrm{N}^{+}$in comparison with the spectra of $\mathrm{keV}$ electron aurorae can be understood in terms of the collisions with atmospheric constituents in this height range, where the ratio of atomic oxygen to molecular oxygen and nitrogen is much greater than at $100-120 \mathrm{~km}$, which is typical of $\mathrm{keV}$ electron aurorae.

The keV neutrals and ions will collisionally excite highexcitation potential lines of $\mathrm{O}, \mathrm{N}, \mathrm{O}^{+}$, and $\mathrm{N}^{+}$, which will radiatively cascade. The $\mathrm{O}^{+}$doublet states will cascade to $\mathrm{O}^{+}\left({ }^{2} P\right)$ and $\mathrm{O}^{+}\left({ }^{2} D\right)$, which may then charge exchange with $\mathrm{N}_{2}$ to give $\mathrm{N}_{2}{ }^{+}$in the $A$ state and emission of the Meinel bands. Transfer of momentum from the primaries to neutral and ion secondaries occurs as a mixed beam of ions and neutrals is formed, as in the model for hydrogen precipitation [Van $Z$ yl et al., 1984]. Thus some $\mathrm{O}^{+}\left({ }^{2} P\right)$ and $\mathrm{O}^{+}\left({ }^{2} D\right)$ will be produced with a few electron volts of energy. By incorporating $0.1 \mathrm{eV}$ or $1.8 \mathrm{eV}$ of kinetic energy as excitation energy, the $\mathrm{O}^{+}$ metastables can charge exchange with $\mathrm{N}_{2}{ }^{+}$to yield $\mathrm{N}_{2}{ }^{+}$ $B \Sigma_{u}{ }^{+}$and hence $\mathrm{N}_{2}{ }^{+} 1 \mathrm{~N}$ emission. This charge exchange mechanism was suggested in the context of twilight emission by Dalgarno and McElroy [1966] and discussed by Broadfoot [1967] and was considered likely to lead to enhanced vibrational excitation. This mechanism would be an additional source of $\mathrm{N}_{2}{ }^{+} 1 \mathrm{~N}$ emission above that produced by direct collisional ionization of $\mathrm{N}_{2}$ by the primaries.

The $\mathrm{H}$ Balmer $\alpha$ and $\mathrm{H}$ Balmer $\beta$ would be the result of collisional excitation of hydrogen primaries when present. The
$\mathrm{He}^{+}$emissions were observed near the magnetic equator and may arise from a more energetic population of trapped ions than the main storm time ring current [Meier and Weller, 1975].

The observation of $\mathrm{He} 10,830-\AA$ emission noted in Table 2 was made by Tinsley [1968] in twilight from a site in New Mexico. An emission rate of $3.8 \mathrm{kR}$ was observed in the north at $60^{\circ}$ zenith angle when the solar zenith angle was $108^{\circ}$. The $K p$ value at the time was $6+$. At the same time in Haute Provence, France, which is about the same dip latitude, G. Weill (personal communication, 1967) observed an auroral type event with a maximum slant emission rate toward the north of $1.3 \mathrm{kR}$ of O I $6300 \AA$.

The characteristics of the low-latitude aurora discussed above are quite similar to those of red type A aurora observed at high latitudes and in particular the aurora of February 10-11, 1958, as recorded at Saskatoon, Canada [Vallance Jones, 1960], and at College, Alaska [Clark and Belon, 1959; Belon and Clark, 1959]. Vallance Jones recorded the enhancement of the $O$ I $7774 \AA$ and $8446 \AA$ lines by about 5 times relative to the $\mathrm{N}_{2}{ }^{+}$Meinel bands in ordinary aurorae, and the $\mathrm{O}^{+}\left({ }^{2} P_{-}{ }^{2} D\right)$ doublet at $7319-7330 \AA$ appeared with an even greater enhancement. In Alaska the nighttime spectra showed the $\mathrm{N}_{2}{ }^{+} 1 \mathrm{~N}$ bands with high vibrational development and prominent atomic and ionic emissions.

\section{Vibrational Development in Low-Latitude Aurorae}

Tinsley et al. [1984] published a spectrum obtained from McDonald Observatory on June 13, 1983, at around 0600 UT (2300 LT). On this occasion the $\mathrm{N}_{2}+1 \mathrm{~N}$ emission predominated. The shadow line was above $800 \mathrm{~km}$, and resonant scattering effects would be small. We have analyzed the relative 

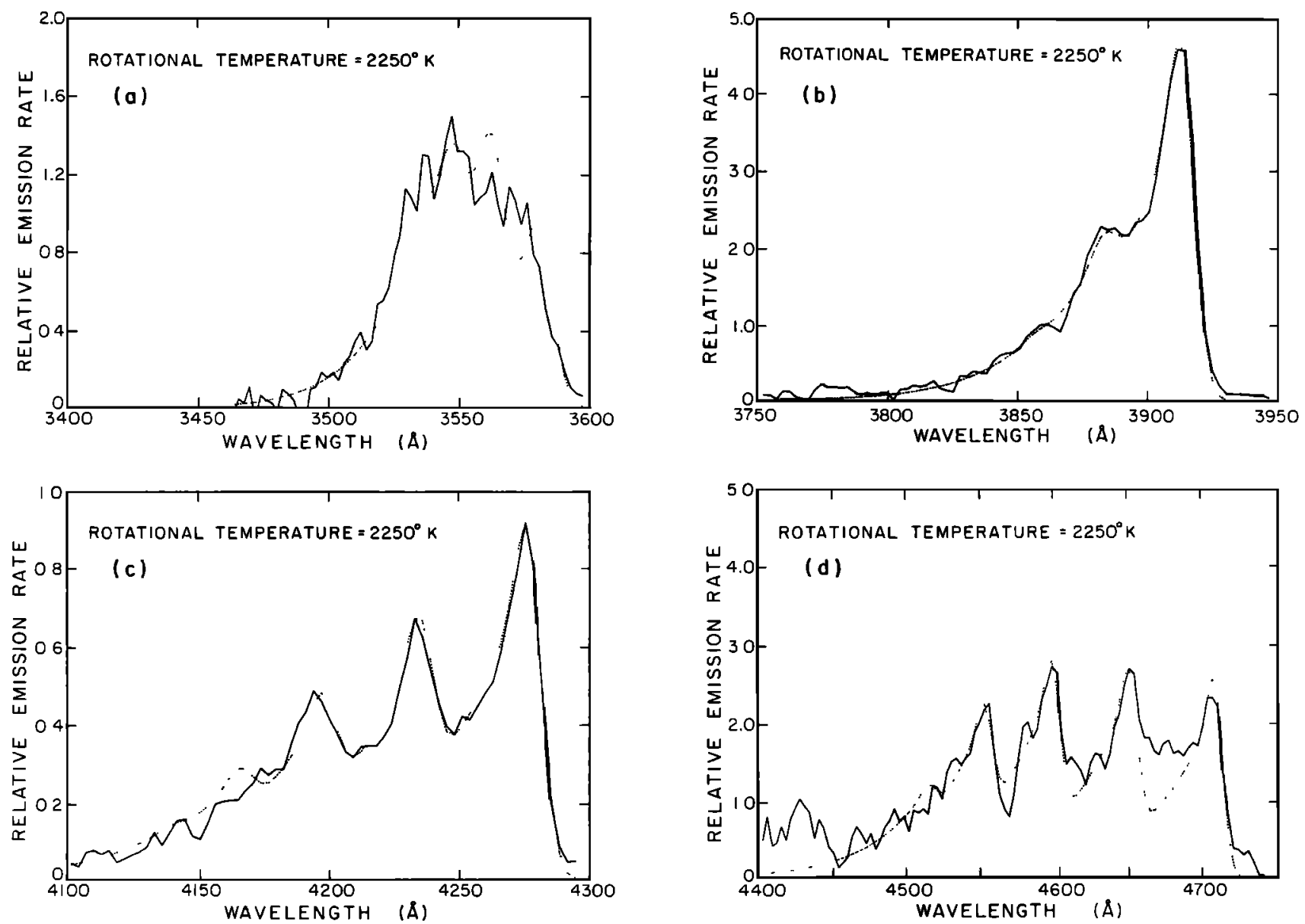

Fig. 1. Comparison of observed (solid line) and synthetic (dotted line) spectra for $\mathrm{N}_{2}{ }^{+} 1 \mathrm{~N}$ bands observed June 13 , 1983, from McDonald Observatory. The $\Delta V=1,0,-1$, and -2 sequences are shown in Figures $1 a, 1 b, 1 c$, and $1 d$, respectively. A spectrum containing the airglow background has been subtracted from the observed data in Figures $1 a, 1 b$, and $1 c$ but not Figure $1 d$. The relative vibrational populations for the synthetic spectra for the $v^{\prime}=0,1,2,3,4$ levels are $50: 21: 16: 10: 3$.

populations of the $\mathrm{N}_{2}{ }^{+} B^{2} \Sigma_{u}{ }^{+}$vibrational levels for the June 13,1983 , spectrum by fitting synthetic spectra to the observed spectra. The results are given in Figure 1 , which shows the first negative band sequences $\Delta v=+1, \Delta v=0, \Delta v=-1$, $\Delta v=-2$. All four synthetic spectra have the same relative populations $\quad N\left(v^{\prime}=0\right): \quad N\left(v^{\prime}=1\right): \quad N\left(v^{\prime}=2\right): \quad N\left(v^{\prime}=3\right)$ : $N\left(v^{\prime}=4\right)$ for the $v^{\prime}=0,1,2,3$, and 4 levels of 50:21:16:10:3. The best fit for rotational temperature was $2250^{\circ} \mathrm{K}$. The overall fit is reasonably good but might be improved by using a nonthermal equilibrium rotational population distribution.

Table 3 lists relative vibrational populations for $\mathbf{N}_{2}{ }^{+} B^{2} \Sigma_{u}$, which have been obtained from laboratory work, theoretical studies, and observations of other auroras and of the June 1983 Texas aurora. The population ratios for the $v^{\prime}=0,1$, and 2 levels for $\mathrm{keV}$ electron excitation in the dark are given by the ratios of the Franck-Condon factors and are about $87: 11: 1$ [Bates, 1949, Table 2]. The increase of population of the upper vibrational levels for collisions of low-energy electrons or the scattering of sunlight on $\mathrm{N}_{2}{ }^{+} X$ depends on the ion lifetime, which is of the order of $10 \mathrm{~s}$ at $300 \mathrm{~km}$ [Broadfoot and Hunten, 1966]. The recent calculation by Degen [1981] yields ratios of $N\left(v^{\prime}=0\right): N\left(v^{\prime}=1\right): N\left(v^{\prime}=2\right)$ of $72: 20: 7$ for an electron flux of $10^{12} \mathrm{~cm}^{-2} \mathrm{~s}^{-1}$, if the ion lifetime $\tau=100 \mathrm{~s}$ corresponding to heights above $400 \mathrm{~km}$. His recalculation of populations produced by scattering of sunlight gives ratios of $71: 17: 8$ for $\tau=2 \mathrm{~s}$ and $52: 24: 15$ for $\tau=100 \mathrm{~s}$. Precipitation of ions or neutrals of velocity of $<10^{8} \mathrm{~cm} \mathrm{~s}^{-1}$ into an atmosphere of pure $\mathrm{N}_{2}$ lead to relative vibrational populations, with populations of the higher vibrational levels increasing as the particle speed is reduced, neutrals having a lower cross section but producing higher vibrational excitation than ions at a given speed. Relevant laboratory studies are those of Fan [1956], Carleton [1957], Moore and Doering [1969a], Birely [1974], and Van Zyl et al. [1983]. The laboratory results for pure $\mathrm{N}_{2}$ are not directly applicable to measured spectra, since a precipitating beam of $\mathrm{O}$ and $\mathrm{O}^{+}$entering the thermosphere with $O$ as the major constitutent above $200 \mathrm{~km}$ would produce a cascade of secondary $\mathrm{O}$ and $\mathrm{O}^{+}$of lower energy in momentum transfer collisions with ambient $\mathrm{O}$ [Torr and Torr, 1979] which, together with slowed down primaries, would contribute to the excitation and produce higher vibrational excitation than initially produced by the primaries. Neither the necessary laboratory measurements nor modeling to establish the primary energy from the observed vibrational distribution has been carried out, but a lower limit for the mean primary energy can be set on the assumption that all the $\mathrm{N}_{2}+1 \mathrm{~N}$ emission is produced by primary $\mathrm{O}^{+}$ions at their initial energy.

The rotational temperature of $2250^{\circ} \mathrm{K}$ which best fitted the observed profiles is much higher than the temperature of about $1000^{\circ} \mathrm{K}$ likely for the ambient thermosphere. The collisions of ions or neutrals with $\mathbf{N}_{\mathbf{2}}$ have been found to increase 
TABLE 3. Relative Vibrational Population for $\mathrm{N}_{2}{ }^{+} B\left(v^{\prime}\right)$

\begin{tabular}{|c|c|c|c|}
\hline & $N\left(v^{\prime}=0\right)$ & $N\left(v^{\prime}=1\right)$ & $N\left(v^{\prime}=2\right)$ \\
\hline $\begin{array}{l}\mathrm{keV} \text { electrons on } \mathbf{N}_{2} \text { (ordinary aurorae) } \\
\left(T_{v}\left(\mathrm{~N}_{2}\right)=1000 \mathrm{~K}[\text { Bates, } 1949 \text {, Table } 11]\right)\end{array}$ & 87 & 11 & 1 \\
\hline $\begin{array}{l}\text { eV electrons on } \mathrm{N}_{2}^{+} X, \tau=100 \mathrm{~s} \\
\left(T_{v}\left(\mathrm{~N}_{2}\right)=1500 \mathrm{~K}, \text { flux } 10^{12} \mathrm{~cm}^{-2} \mathrm{~s}^{-1}\right)\end{array}$ & 72 & 20 & 7 \\
\hline $\begin{array}{l}\text { Sunlight on } \mathrm{N}_{2}^{+} X, \tau=2 \mathrm{~s} \\
\quad[\text { Degen, } 1981]\end{array}$ & 71 & 17 & 8 \\
\hline $\begin{array}{l}\text { Sunlight on } \mathrm{N}_{2}^{+} X, \tau=100 \mathrm{~s} \\
\quad[\text { Degen, } 1981]\end{array}$ & 52 & 24 & 15 \\
\hline $\begin{array}{l}\text { Neutrals, } 4.4 \times 10^{7} \mathrm{~cm} \mathrm{~s}^{-1} ; \text { ions, } 1.7 \times 10^{7} \mathrm{~cm} \mathrm{~s}^{-1} \\
\quad[\text { Moore and Doering, } 1969 a ; \text { Birely, 1974; Van Zyl et al., 1983] }\end{array}$ & 51 & 24 & 16 \\
\hline $\begin{array}{l}\text { Neutrals, } 2.8 \times 10^{7} \mathrm{~cm} \mathrm{~s}^{-1} \text {; ions, } 1 \times 10^{7} \mathrm{~cm} \mathrm{~s}^{-1} \\
\quad[\text { Moore and Doering, 1969a; Birely, 1974; Van Zyl et al., 1983] }\end{array}$ & 40 & 26 & 20 \\
\hline $\begin{array}{l}\text { Haute Provence, observed April 17-18, } 1947 \\
\text { (judged not sunlit [Barbier, 1947]) }\end{array}$ & 40 & 26 & 18 \\
\hline $\begin{array}{l}\text { Texas, observed June } 13,1983 \\
\text { (not sunlit, not red [Tinsley et al., 1984]) }\end{array}$ & 50 & 21 & 16 \\
\hline $\begin{array}{l}\text { Alaska, observed February 10, } 1958 \\
\text { (sunlit, red type A [Clark and Belon, 1959]) }\end{array}$ & 52 & 24 & 15 \\
\hline $\begin{array}{l}\text { Logan, observed September } 21-22,1982 \\
\text { (not sunlit }[\text { Torr and Torr, 1984]) }\end{array}$ & 68 & 17 & 10 \\
\hline $\begin{array}{l}\text { Alaska, observed February 10, } 1958 \\
\text { (not sunlit, red type A [Clark and Belon, 1959]) }\end{array}$ & 71 & 19 & 7 \\
\hline $\begin{array}{l}\text { Alaska, observed March } 8,1978 \\
\text { (not sunlit, proton aurora [Sivjee, 1980]) }\end{array}$ & 77 & 19 & $\cdots$ \\
\hline
\end{tabular}

the excitation of the higher rotational levels [Moore and Doering, 1969b].

A further complication for interpretation of observations is that the production of $\mathrm{O}^{+}\left({ }^{2} P\right)$ and $\mathrm{O}^{+}\left({ }^{2} D\right)$ in the cascade with more than a few electron volts of kinetic energy makes possible the production of vibrationally and rotationally excited $\mathrm{N}_{2}{ }^{+}$by the charge exchange mechanism, and again there is a lack of laboratory measurements and models. The very strong $\mathrm{O}^{+}\left({ }^{2} P_{-}^{2} D\right)$ emission at $7319-7330 \AA$ observed by Vallance Jones [1960] is an indication of the need of further study of this mechanism.

For the Texas aurora of June 13,1983, the absence of sunlight and of sufficient low-energy electrons to excite appreciable $6300-\AA$ emissions rules out resonant scattering and lowenergy electrons as $\mathrm{N}_{2}{ }^{+}$excitation mechanisms. The vibrational population ratios of $50: 21: 16$ can be compared to the laboratory data for heavy ions on $\mathrm{N}_{2}$ [Moore and Doering, $1969 a]$ and lead to a lower limit for the mean primary velocity of $2 \times 10^{7} \mathrm{~cm} \mathrm{~s}^{-1}$ (mean primary energy $3 \mathrm{keV}$ ) for $\mathrm{O} / \mathrm{O}^{+}$ primaries.

The Haute Provence 1947 aurora with population ratios $40: 26: 18$ [Bates, 1949] was judged by Barbier [1947] not to be sunlit, although Seaton [1956] questioned this. However, the vibrational excitation is too high to be produced by sunlight on the basis of Degen's [1981] calculations and also too great to be explained by a low-energy electron flux, unless it was significantly greater than $10^{12} \mathrm{~cm}^{-2} \mathrm{~s}^{-1}$, or the $\mathrm{N}_{2}^{+}$ lifetime significantly longer than $100 \mathrm{~s}$. Again, an explanation in terms of a precipitating $\mathrm{O} / \mathrm{O}^{+}$flux is indicated, in this case with a lower limit on mean primary energy of about $1 \mathrm{keV}$.

The aurora of February 10, 1958, was observed at many low-latitude sites, with characteristic low-latitude spectral features, and also in Alaska, where a series of spectra were taken which also showed the features characteristic of low-latitude aurorae, rather than the $\mathrm{keV}$ electron aurorae ordinarily seen at those latitudes. The spectra taken in sunlight showed a vibrational population ratio of $52: 24: 15$, which can be explained by the action of sunlight according to Degen [1981] if the height were above $400 \mathrm{~km}$ and the $\mathrm{N}_{2}{ }^{+} X$ lifetime of the order of $100 \mathrm{~s}$. However, a contribution from low-energy electrons and ion/neutral precipitation is also plausible, especially since the sunlit aurora in the 400 - to $500-\mathrm{km}$-height region observed by Vallance Jones and Hunten [1960] had vibrational population ratios of only $71: 17: 8$.

The aurora of September 21-22, 1982, observed at Logan, Utah, was found to have a ratio of the (0-1) to (1-2) bands of $\mathrm{N}_{2}{ }^{+} 1 \mathrm{~N}$ of typically 3-3.5 [Torr and Torr, 1984] (see also Ishimoto et al. [1986]). This and the ratio of the (0-1) to (2-3) bands of about 7 in Figure 4 of Torr and Torr [1984] correspond to a population ratio of about $68: 17: 10$ and by referring to Moore and Doering [1969a] translates into a lower limit for the mean primary velocity of about $4 \times 10^{7} \mathrm{~cm} \mathrm{~s}^{-1}$ and a mean $\mathrm{O}^{+}$primary energy of about $13 \mathrm{keV}$. Torr and Torr [1984] argued that the effects of any flux of low-energy electrons on the vibrational distribution of $\mathrm{N}_{2}{ }^{+}$emission was likely to have been small in view of the absence of significant vibrational excitation of the $\mathbf{N}_{2}$ second positive bands.

The aurora of February 10-11, 1958, was also observed in the dark atmosphere by Clark and Belon [1959] and showed a population ratio of $71: 19: 7$, with less development than for the earlier sunlit aurora. Degen [1981] interpreted this as due to low-energy electrons, and ion/neutral precipitation is an additional mechanism that cannot be ruled out. If ion/neutral precipitation was dominant, then a lower limit for the mean primary energy of $\mathrm{O}^{+}$would be about $15 \mathrm{keV}$. For comparison, proton aurora observed by Sivjee [1980] had a relative vibrational population ratio for $N\left(v^{\prime}=0\right): N\left(v^{\prime}=1\right)$ of $77: 19$, and the analysis in conjunction with laboratory results implied the precipitation of protons of energy of $\sim 1.2 \mathrm{keV}$. The vibrational development is still about twice as much as for a typical $\mathrm{keV}$ electron aurora with population ratios of about 87:11:1.

\section{LAtitude VARIATIONS IN $\mathrm{N}_{2}+1$ N Emission}

The population ratios derived from various observations of nonsunlit aurora in Table 3 shows an interesting trend with dip latitude of the observation site. The auroras of the lowest latitude sites, Texas and Haute Provence (both near dip lati- 


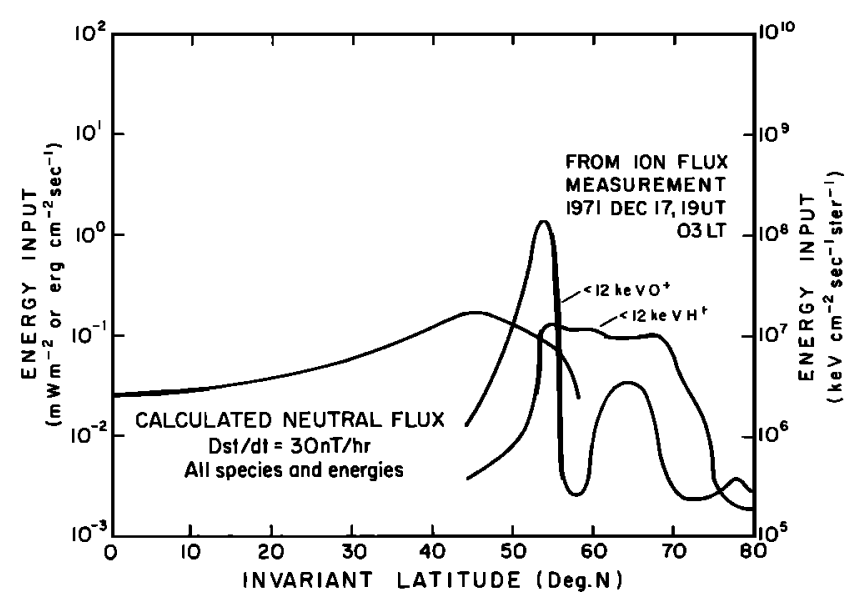

Fig. 2. Representative latitude variation of energy input of ion and neutral precipitation. The ion flux measurements were made by Sharp et al. [1976b] in the energy range $0.7-12 \mathrm{keV}$, and the neutral flux is from Tinsley [1979] for a ring current at $L=4$.

tude $\sim 40^{\circ}, L \sim 1.8$, had the greatest vibrational development; that of Logan (dip latitude $\sim 50^{\circ}, L \sim 2.4$ ) had an intermediate amount, and Clark and Belon's [1959] spectrum from College, Alaska (dip latitude $\sim 65^{\circ}, L=5.4$ ), had the least vibrational development.

The trend in decreasing vibrational development with increasing latitude is consistent with two trends seen in the satellite data of Sharp et al. [1976b]. These are (1) an increase in the mean energy of the precipitating $\mathrm{O}^{+}$ions with latitude and (2) an increase in the fraction of $\mathrm{H}^{+}$in the total flux at a given energy. Their Figure 2 shows an energy spectrum peaked near $10 \mathrm{keV}$ at the highest latitude sampled ( $L=9.4)$, changing into a much softer spectrum with a peak near $1 \mathrm{keV}$ for the lowest latitude sampled $(L=2.8)$. Also, their Figure 4 shows the $\mathrm{H}^{+}$energy flux increasing with respect to the $\mathrm{O}^{+}$ energy flux toward higher latitudes. Neither of the above trends is very smooth, and the optical and particle comparisons involve a number of different events, but taken together, they add support to the concept of ion/neutral precipitation being the source of the observed high vibrational excitation of $\mathrm{N}_{2}+1 \mathrm{~N}$.

The latitude gradients in intensity of $\mathrm{N}_{2}{ }^{+} 1 \mathrm{~N}$ emission are also worth examining. The observations from Haleakala on April 13, 1981, showed little intensity difference between looking north and south at $70^{\circ}$ zenith angle [Rohrbaugh et al., 1983], although those of July 14, 1982, show about 2 times greater emission in the north. There was no appreciable latitude gradient in the July 13-14, 1982, results from Brazil. These results are consistent with the relatively small gradients predicted from a theoretical model for neutral atom precipitation [Tinsley, 1979].

The longitude separations among the sites at McDonald Observatory (Texas), Haleakala (Hawaii), and Cachoeira Paulista (Brazil) are too great to allow latitude gradients in emission rates to be determined among these sites from simultaneous data. Comparisons of time variations of emission rates and the magnetic variations with which they are correlated show that the longitudinal scale of the variations is smaller than the separation among the three sites. In general terms one can say that in Texas, for stronger magnetic storms the emission rates of the $\mathrm{N}_{2}{ }^{+} 1 \mathrm{~N}$ bands reach hundreds to thousands of rayleighs, whereas in Hawaii and Brazil a few rayleighs to a few tens of rayleighs are all that appear.
The models of Tinsley [1979] predict latitude gradients in the precipitation of energetic neutral atoms such that the expected fluxes in the region observed from McDonald Observatory (near $40^{\circ}$ dip latitude) would be expected to be no more than 4 times greater than the fluxes observed from the two equatorial stations, at $5^{\circ}-25^{\circ}$ dip latitude. The theoretical ratio depended on the $L$ shell and the length of time the pitch angle distribution had been evolving from a distribution initially isotropic to the loss cone, defined by a mirror height of $375 \mathrm{~km}$. The general observational result that emission rates at McDonald Observatory (and other sites of similar dip latitude such as Haute Provence) are hundreds of times those at the equatorial sites implies that direct ion precipitation is required there in addition to the neutral atom precipitation extending from the equator to mid-latitudes. The direct ion precipitation would begin at dip latitudes near $40^{\circ}$ and extend up to high latitudes as measured by Sharp et al. [1976b].

Figure 2 illustrates the above concept of the latitude variation of the ion and neutral precipitation. The measurements of ion flux were taken from Sharp et al. [1976b, Figures 7 and 9], and the calculated neutral flux energy input is from Tinsley [1979] for energy loss by charge excharge equivalent to a $30-n T / h$ decay rate for the ring current. The ring current is assumed to have a pitch angle distribution isotropic to a loss cone at $375 \mathrm{~km}$ and to be located on a drift shell of $L=4$, representative of a more realistic ring current distributed over drift shells from $L=3$ to $L=5$.

During direct precipitation of ions some process must be continually repopulating the part of the ion velocity distri-

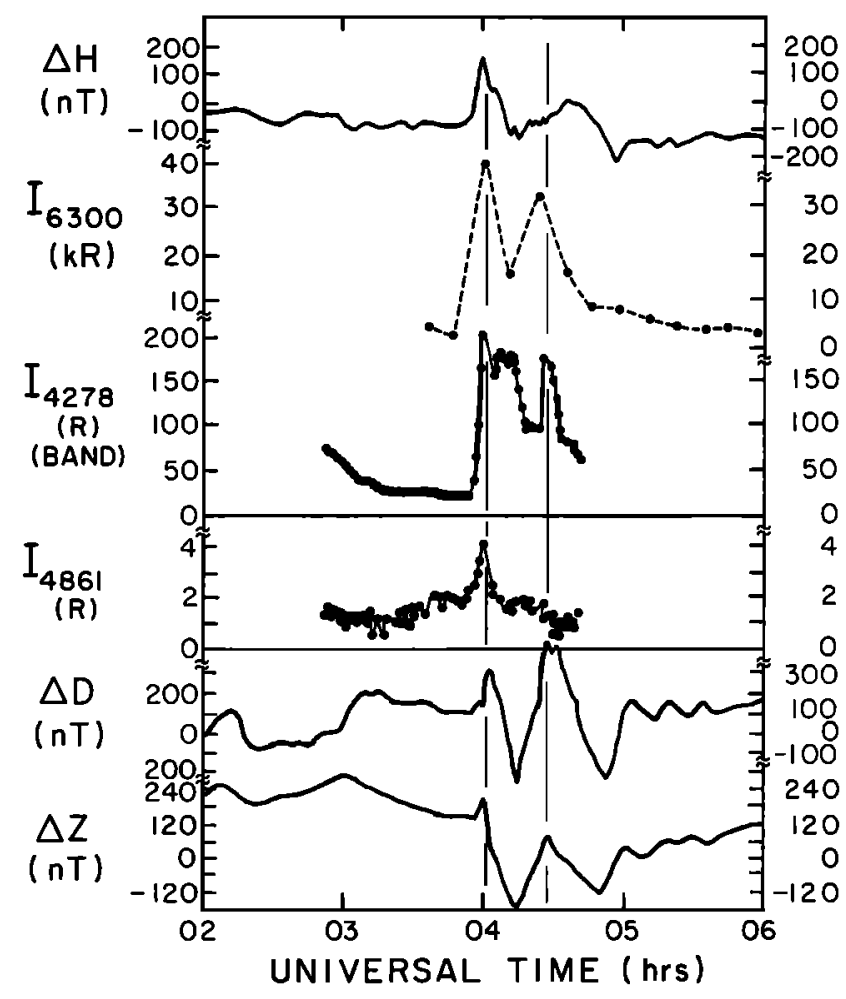

I3 APRIL 198I UT

Fig. 3. Magnetograms from Boulder, Colorado, compared with time variations of emissions observed April 13, 1981. The 4287- $\AA$ and 4861- $\AA$ emissions were observed from McDonald Observatory, Texas, and the $6300-\AA$ emission from McColly Observatory, Montana, both looking into a volume of space almost directly above Boulder. 
bution within the loss cone. Processes which populate the loss cone during conditions when low-latitude aurorae are detected (i.e., during substorms or the main phases of magnetic storms) include the lowering of mirror heights by adiabatic inward convection and strong and weak pitch angle diffusion [Tinsley and Akasofu, 1982]. The faster the rate of lowering mirror heights of ions, the greater the fraction that will be precipitated directly rather than as energetic neutrals following charge exchange. For weaker magnetic activity one might expect that the time constant for lowering of mirror heights would be longer than for stronger activity, and then energetic neutral precipitation would predominate over direct ion precipitation at dip latitudes of $40^{\circ}$ and greater, and the ratio of intensity above $40^{\circ}$ would not be so large in comparison to the equatorial intensity. We do not have sufficient data to test this prediction as yet.

\section{Time Variations and CURRENT SySTEMS}

\section{Central U.S. Data}

An analysis of the time variations of emission leatures with respect to each other and with respect to magnetic and ionospheric data is relevant to identifying the excitation process and to how the precipitation processes fit into the overall picture of substorm development and ring current losses. Figure 3 shows time variations of emissions observed April 13, 1981, at McDonald Observatory. The $\mathrm{N}_{2}{ }^{+} 1 \mathrm{~N}(0,1)$ band at $4278 \AA$ and the $\mathrm{H}$ Balmer $\beta$ line at $4861 \AA$ were observed $30^{\circ}$ above the northern horizon. The [O I] $6300-\AA$ emission was observed from McColly Observatory, Montana (latitude $48.6^{\circ} \mathrm{N}$, longtiude $107.1^{\circ} \mathrm{W}$ ), looking south at $80^{\circ}$ zenith angle and intercepting the line of sight from McDonald observatory at $400-\mathrm{km}$ altitude. The optical time variations are compared with magnetic variations measured from Boulder, a site almost directly under the volume of the thermosphere being observed. A good correlation of the intensity variations with

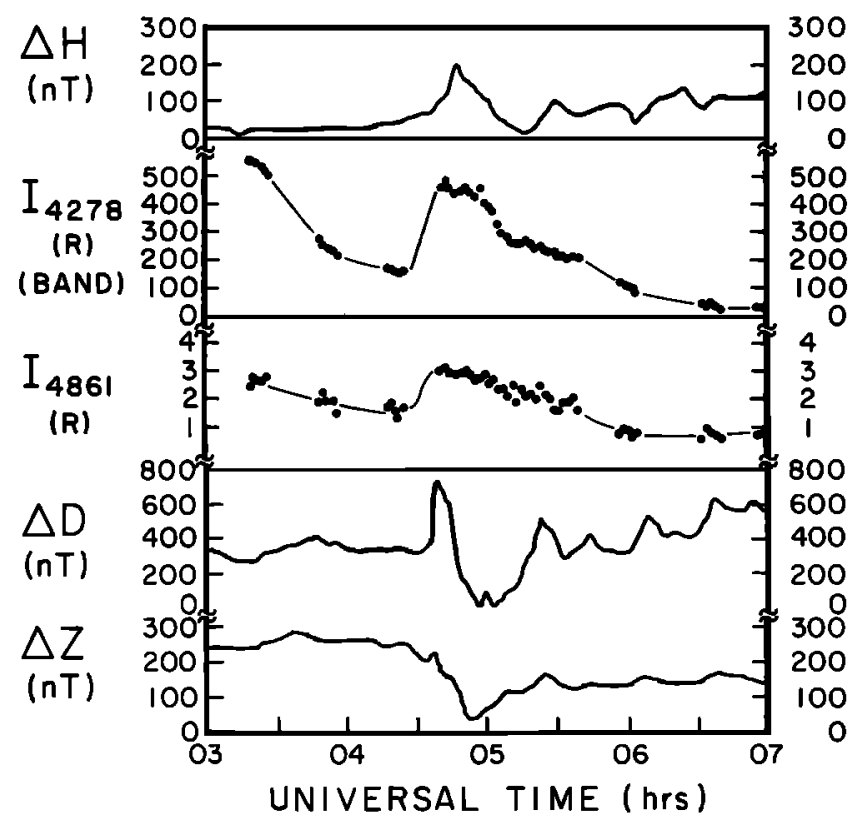

\section{JULY 1982 UT}

Fig. 4. Magnetograms from Boulder, Colorado, compared with time variations of emission observed July 14, 1982, from McDonald Observatory.

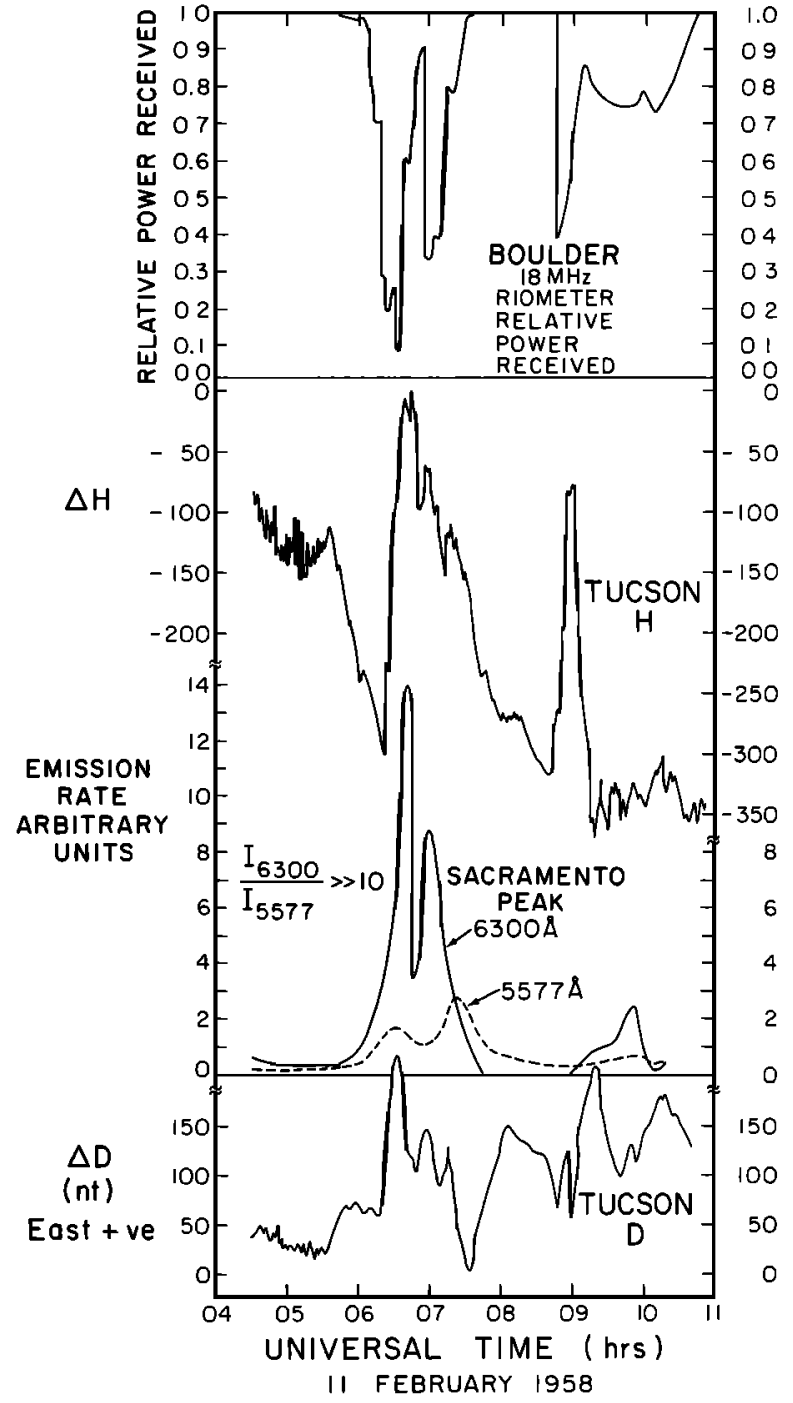

Fig. 5. Magnetograms from Tucson, Arizona, compared with time variations of emission observed from Sacramento Peak, New Mexico, UT February 11, 1958, and with ionospheric absorption recorded on a riometer at Boulder, Colorado.

the disturbance magnetic field can be seen. The absence of $\mathbf{H}$ Balmer $\beta$ during the latter part of the event can be understood as a more rapid loss of hydrogen ions from the inner ring current than oxygen or helium ions, owing to the larger charge exchange cross section for $\mathrm{H}$ than $\mathrm{O}$. An alternative interpretation is that the accumulation of $\mathrm{O}^{+}$ions in the trapped population from an ionospheric source eventually outnumber the initial $\mathrm{H}^{+}$from a solar wind source. Similar good correlations between optical and magnetic time variations apply to July 14, 1982, data (Figure 4). In both cases the precipitation is associated with positive excursions in the $H$ trace and first positive then negative excursions in the $D$ trace of the magnetograms from nearby observatories.

An additional example is the February 10-11, 1958, aurora observed from Sacramento Peak, New Mexico, by Manrung and Pettit [1959]. Their optical data have been compared with Tucson magnetograms in Figure 5, and the same relationship to $\Delta H$ and $\Delta D$ can be seen as for the 1981-1982 storms. The $6300-\AA$ and $5577-\AA$ emission rates are whole-sky averages. The $6300-\AA$ intensities reached at least a factor of 1000 greater than the normal airglow intensities for that time, and the 


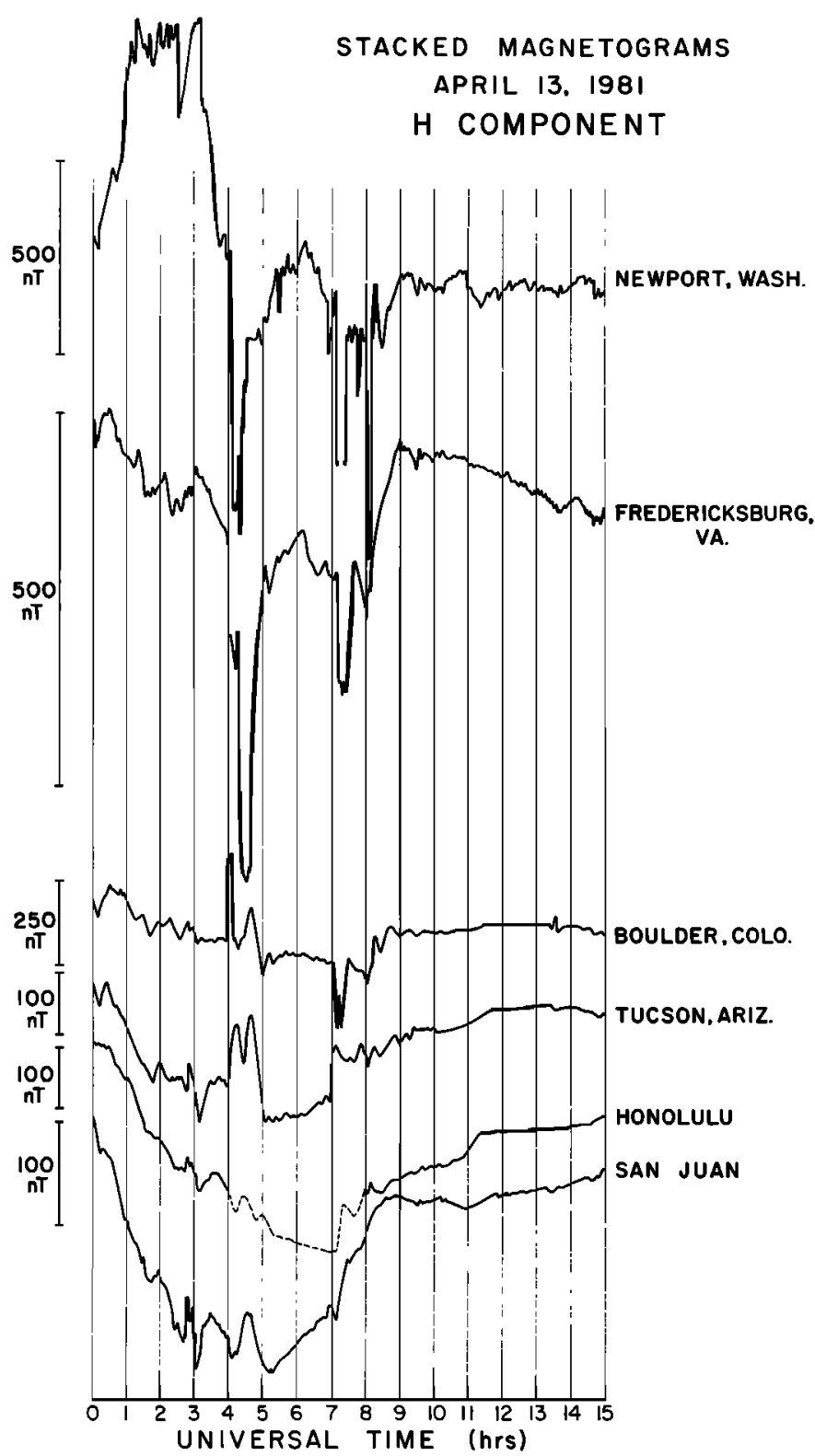

Fig. 6. Stacked magnetograms from observatories across the United States showing the $H$ component for the April 13, 1981, events. The observations of Figure 3 correspond to the substorm of $0400-0500 \mathrm{UT}$, and those of Figure 14 to the substorm of $0700-0800$ UT. The $H$ trace saturated in Honolulu, and the dashed part of the curve is inferred from the Tahiti trace.

$5577-\AA$ emission rates a factor of 10 above normal. The $I(6300$ $\AA)$ to $I(5577 \AA)$ intensity ratio was greater than 10 , indicating the presence of a large flux of low-energy electrons. In addition, Figure 5 shows the large increase in ionospheric absorption of $18 \mathrm{MHz}$ on the Boulder riometer located $8^{\circ}$ poleward of Sacramento Peak [Warwick, 1958]. Absorption of cosmic noise at these frequencies is usually produced by enhanced ionization at $E$ region heights or below [Little and Leinbach, 1958]. It indicates the presence of more energetic particles penetrating more deeply into the atmosphere than low-energy electrons and perhaps heavy particles presumed responsible for the lower latitude display.

Sets of stacked magnetograms from observatories across the United States for periods covering the April 1981 and July 1982 storms are given in Figures 6, 7, 8, 9, 10, and 11. Only the perturbations in the components are shown, and a large baseline value has been subtracted here and in other figures in the paper, where the perturbations in the components are labeled $\Delta H, \Delta D$, and $\Delta Z$. Figure 12 shows the location of most of the observatories on a chart of magnetic dip angle. The observatories from which records are shown are, in order of decreasing dip latitude, Newport, Washington; Fredericksburg, Virginia; Boulder, Colorado; Tucson, Arizona; Honolulu, Hawaii; and San Juan, Puerto Rico. The substorms of interest for the observations of Figures 3 and 4 are those of 0400-0500 UT on April 13 and 0500-0600 UT on July 14. Examination of Figures 6 and 7 shows that the positive excursions in $H$ at the lower latitude observatories at the time of the optical emissions are associated with negative $H$ excursions at higher latitude observatories in the same longitude sector, i.e., at the time of occurrence of large substorms.

Figures 8 and 9 show $D$ component magnetograms in order of increasing east longitude. The signature in $D$ is such that the change from eastward perturbation to westward perturbation occurs close to the time of peak amplitude of the perturbation in $H$. The eastward magnetic field perturbation is associated with the growth of the substorm current system,

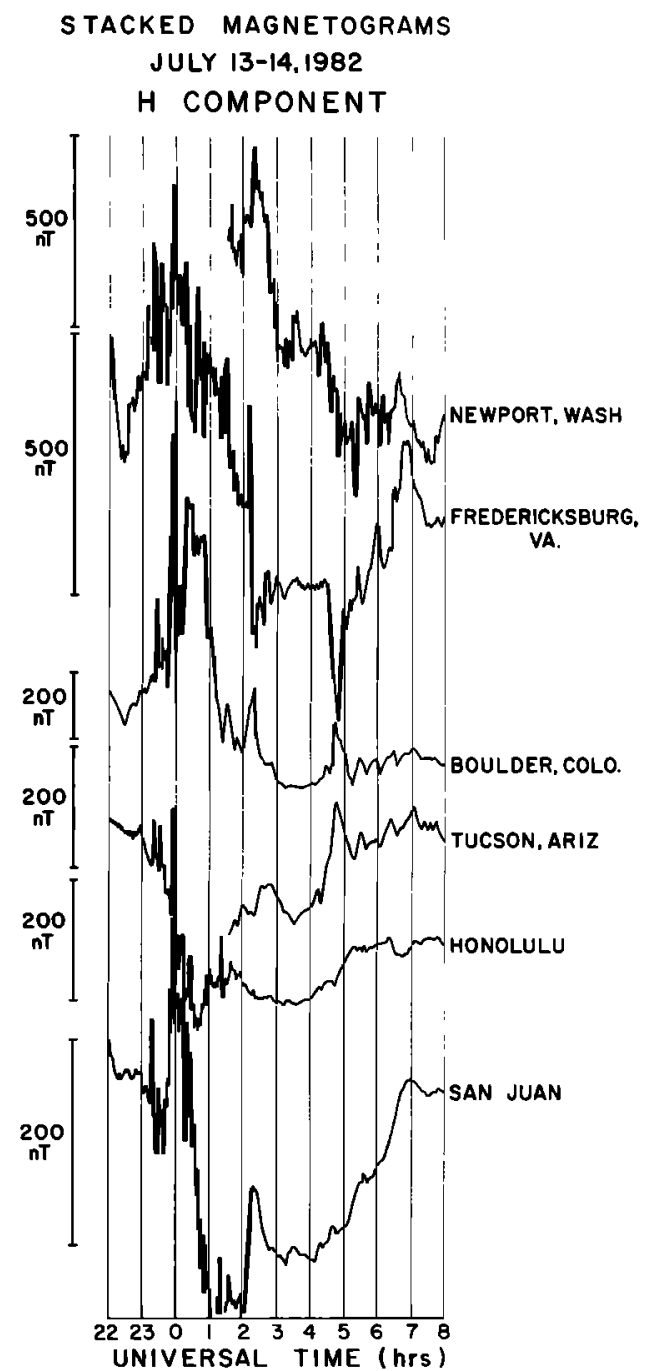

Fig. 7. Stacked magnetograms showing the $\mathrm{H}$ component for the July 14, 1982, events. The observations of Figure 4 correspond to the substorm of $0400-0600 \mathrm{UT}$, and those of Figure 15 to the substorm at about $0000 \mathrm{UT}$. 
STACKED MAGNETOGRAMS

APRIL 13, 198I

D COMPONENT

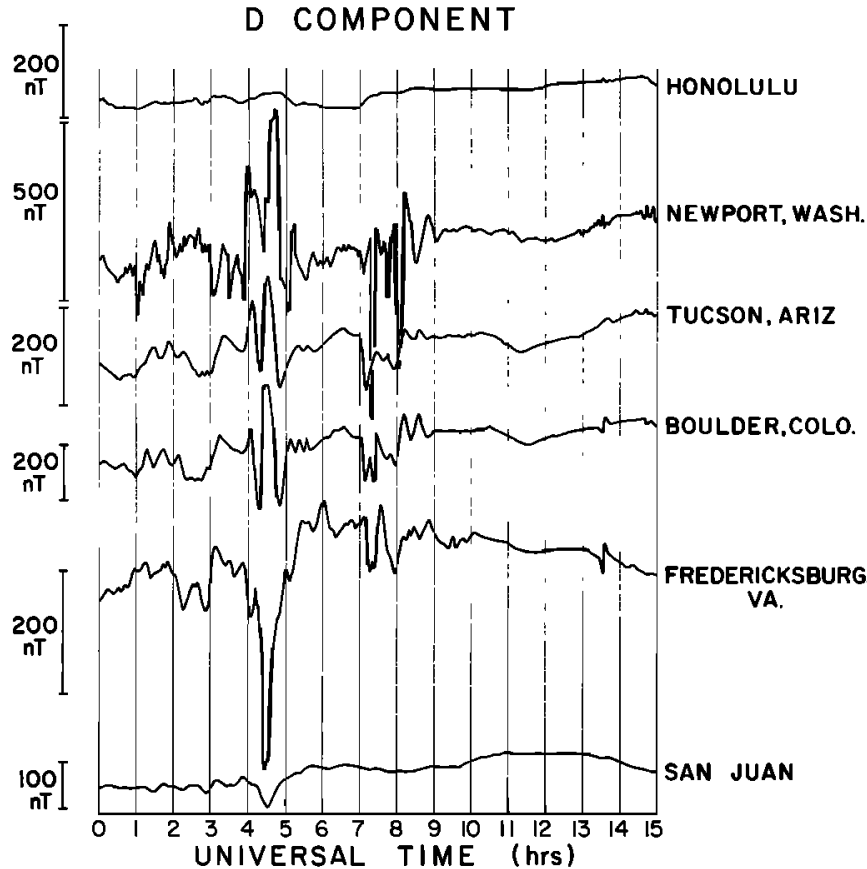

Fig. 8. Stacked magnetograms showing the $D$ component for the April 13, 1981, events.

and the westward magnetic field perturbation to its decay. The signatures of the substorms in the $Z$ component are shown in Figures 10 and 11 . Generally, there is a decrease in the $Z$ component at all latitudes during the events.

The magnetograms from low-latitude stations show the positive $\Delta H$ of an eastward electrojet, and the higher latitude

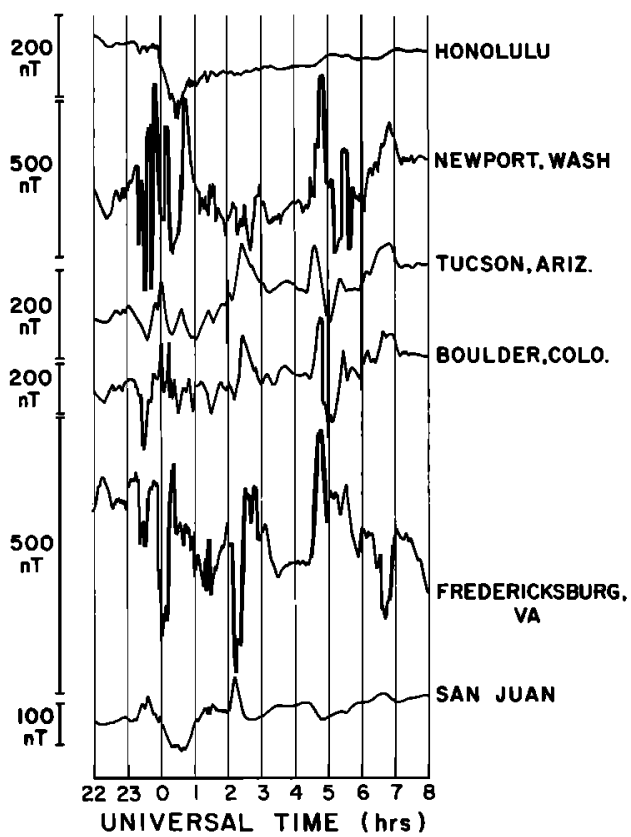

Fig. 9. Stacked magnetograms showing the $D$ component for the July 14, 1982, events.

\section{STACKED MAGNETOGRAMS}

APRIL 13, 1981

$Z$ COMPONENT

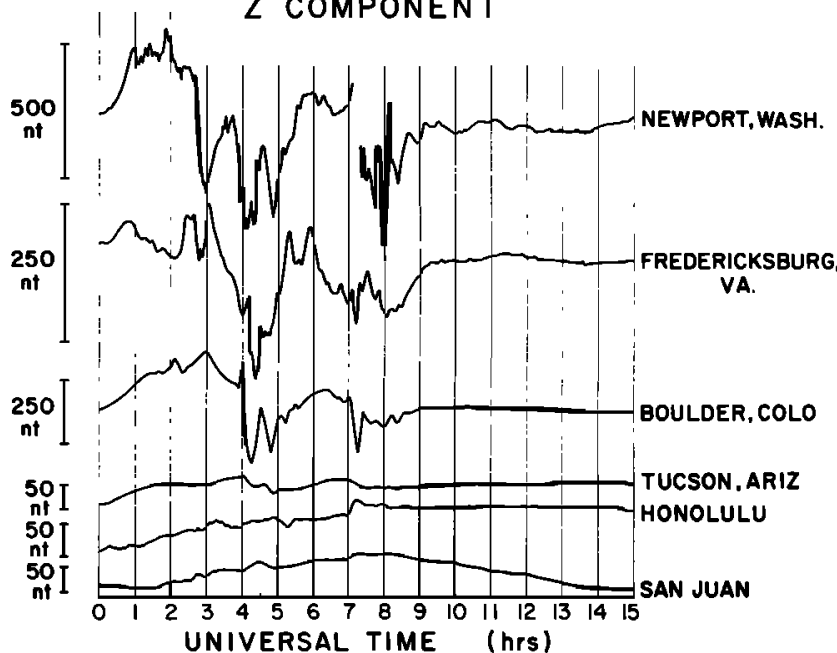

Fig. 10. Stacked magnetograms showing the $Z$ component for the April 13, 1981, event.

magnetograms in the same longitude sector show the large negative $\Delta H$ of an intense westward electrojet in accordance with the normal substorm pattern [Ahn et al., 1984]. However, the large $D$ oscillation from eastward to westward does not appear in the normal pattern and appears to be characteristic of the rapid growth and rapid decay of these unusually large substorms. This rapidity is perhaps the most important factor responsible for the injection of the positive ions to unusually low latitudes, for the shielding currents which flow will not have sufficient time to halt the penetration of the electric fields driving the ions. (A discussion of the penetration of highlatitude electric fields into low latitudes is given by Kamide and Matsushita [1981]). The geometry of these currents, some of which may be carriers of the large fluxes of low-energy electrons which are implied by the optical observations, remains to be worked out

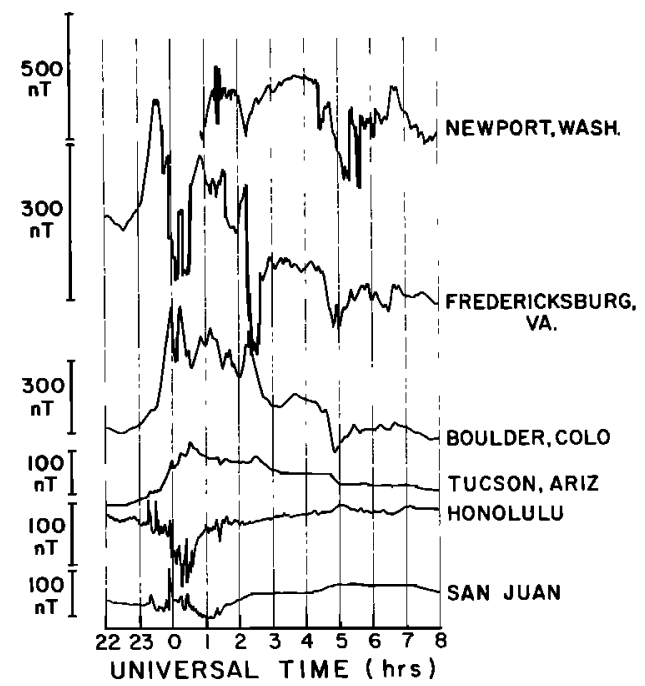

Fig. 11. Stacked magnetograms showing the $Z$ component for the July 14, 1982, event. 


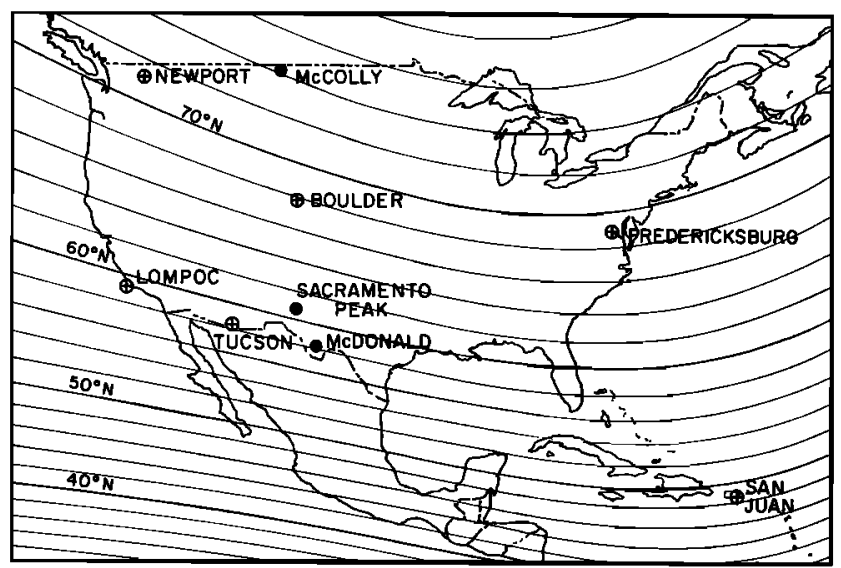

Fig. 12. Map showing location of magnetic and optical observatories in the continental United States and Puerto Rico. The contours of dip angle are taken from the map compiled by the U.S. Geological Survey [1975]. Dip angles of $60^{\circ}$ and $70^{\circ}$ correspond to $41^{\circ}$ and $54^{\circ}$ dip latitude, respectively.

\section{Data From Mount Haleakala, Hawaii, and} Cachoeira Paulista, Brazil

Figure 13 shows a comparison of emission rate variations observed at Mount Haleakala, Hawaii, for the July 14, 1982, magnetic storm with magnetograms from Honolulu and Newport. A substorm at the later universal time of 0900-1100 UT is involved on account of the longitude difference. The relationship of the emission rate variations to the local (Honolulu) $\Delta H$ and $\Delta D$ charges is similar to that observed in Texas and New Mexico, and the Newport variations fit the pattern of the higher latitude substorm signatures. For the storm of

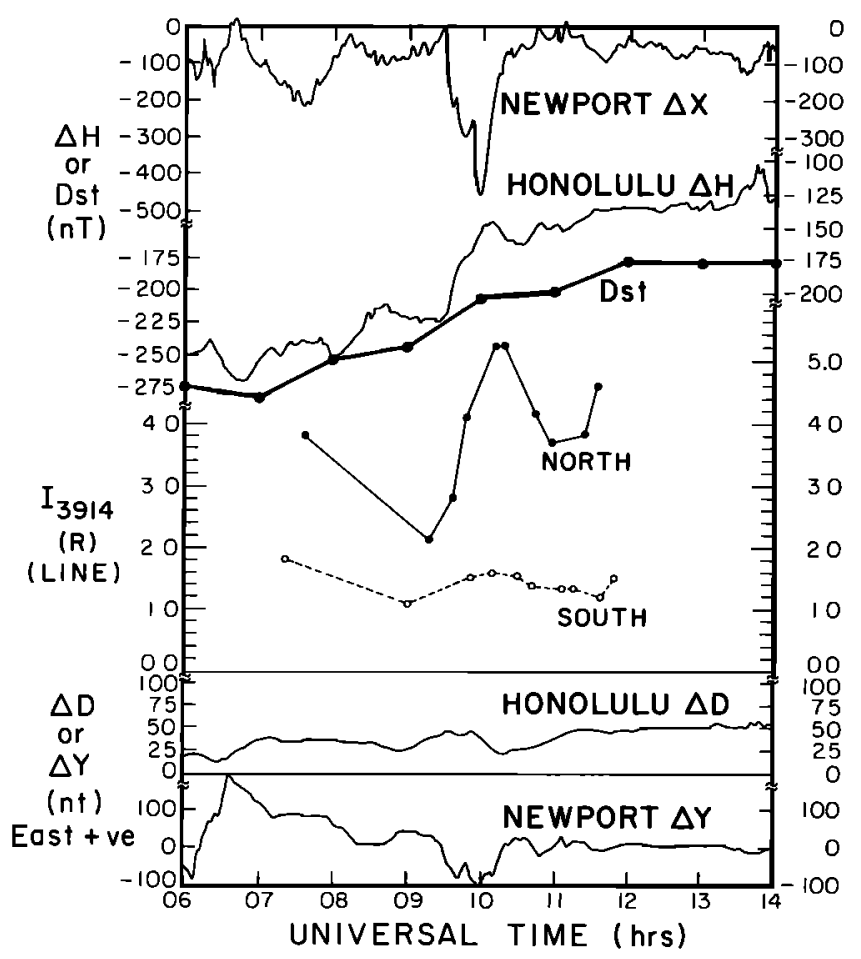

14 JULY 1982 HALEAKALA EMISSIONS COMPARED TO NEWPORT AND HONOLULU MAGNETOGRAMS

Fig. 13. Magnetograms from Honolulu and Newport compared with time variations of emissions observed on July 14, 1982, from Haleakala, Hawaii.
April 13, 1981, shown in Figure 14, the Honolulu $H$ trace went off scale, and a comparison of emission rate variations is made with the two stations of Newport and Lompoc on the west coast of the continental United States (see Figure 12). The $\Delta X$ and $\Delta Y$ signatures are in accordance with the pattern established for $\Delta H$ and $\Delta D$, except that the Lompoc $\Delta Y$ does not first show a positive excursion in $Y$ before the negative emission occurs. Figure 15 compares emissions observed for the July 13-14, 1982, magnetic storm in Cachoeira Paulista, Brazil (latitude $22.7^{\circ} \mathrm{S}$, longitude $45.0^{\circ} \mathrm{W}$, dip latitude $12^{\circ} \mathrm{S}$ ) with magnetograms from the nearby station of Vassouras (latitude $23^{\circ} \mathrm{S}$, longitude $46^{\circ} \mathrm{W}$ ). Corresponding mid-latitude magnetograms are given in Figures 7, 9, and 11.

As in the case of the central U.S. data the precipitation occurs at the time of a strong westward electrojet at midlatitudes produced by a substorm. The low to equatorial latitude region would be more effectively shielded from substormassociated electric fields than the mid-latitude region, and local ionospheric currents would be expected to be small. Thus the $D$ signature apparently represents the integrated effect of the distant magnetospheric-ionospheric current systems associated with the substorm.

Figures $13-15$ also show the $D$ st parameter, which is a measure of the total energy content of the trapped particles which constitute the ring current, obtained from the longitudinal average of $\Delta H$ values measured at low-latitude observatories. (For a definition of $D s t$ and other magnetic parameters and their relationship to storm time current systems, see, for example, Akasofu and Chapman [1972].) As can be seen from the

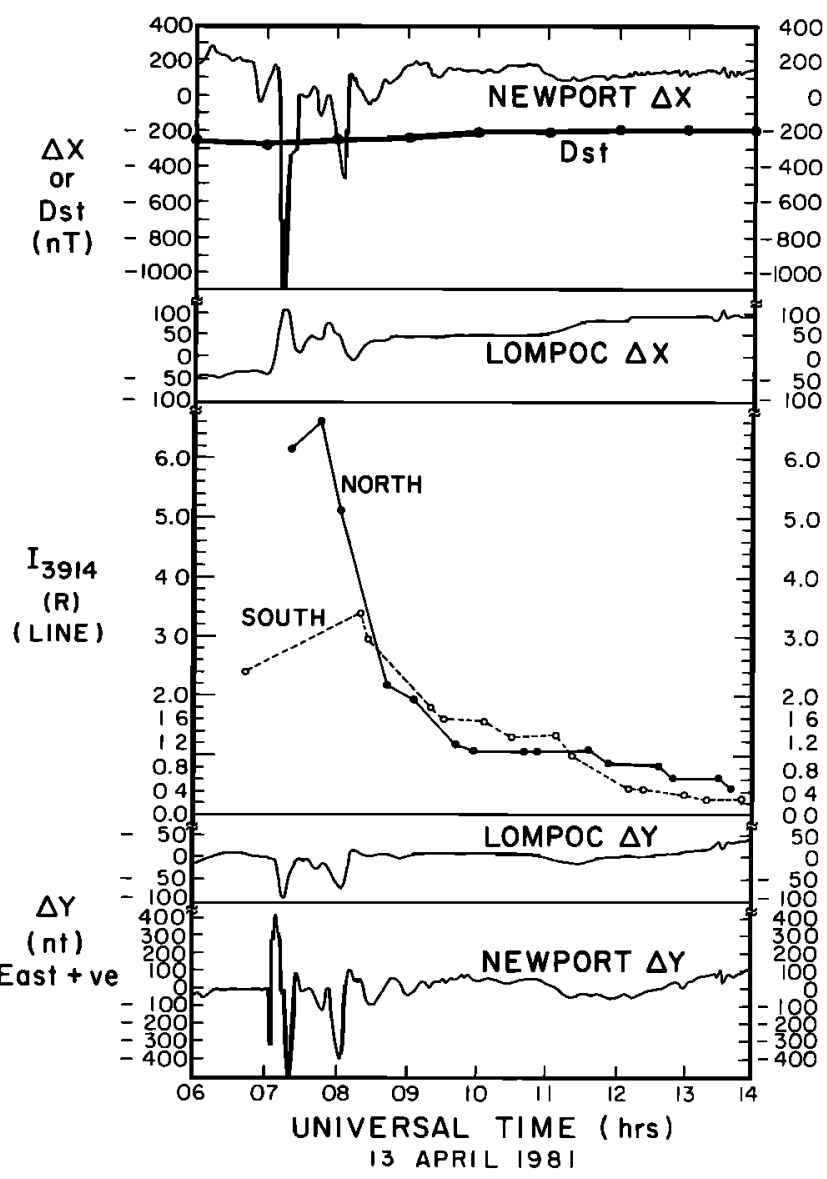

Fig. 14. Magnetograms from Lompoc and Newport compared with time variations of emission observed on April 13, 1981, from Haleakala, Hawaii. 


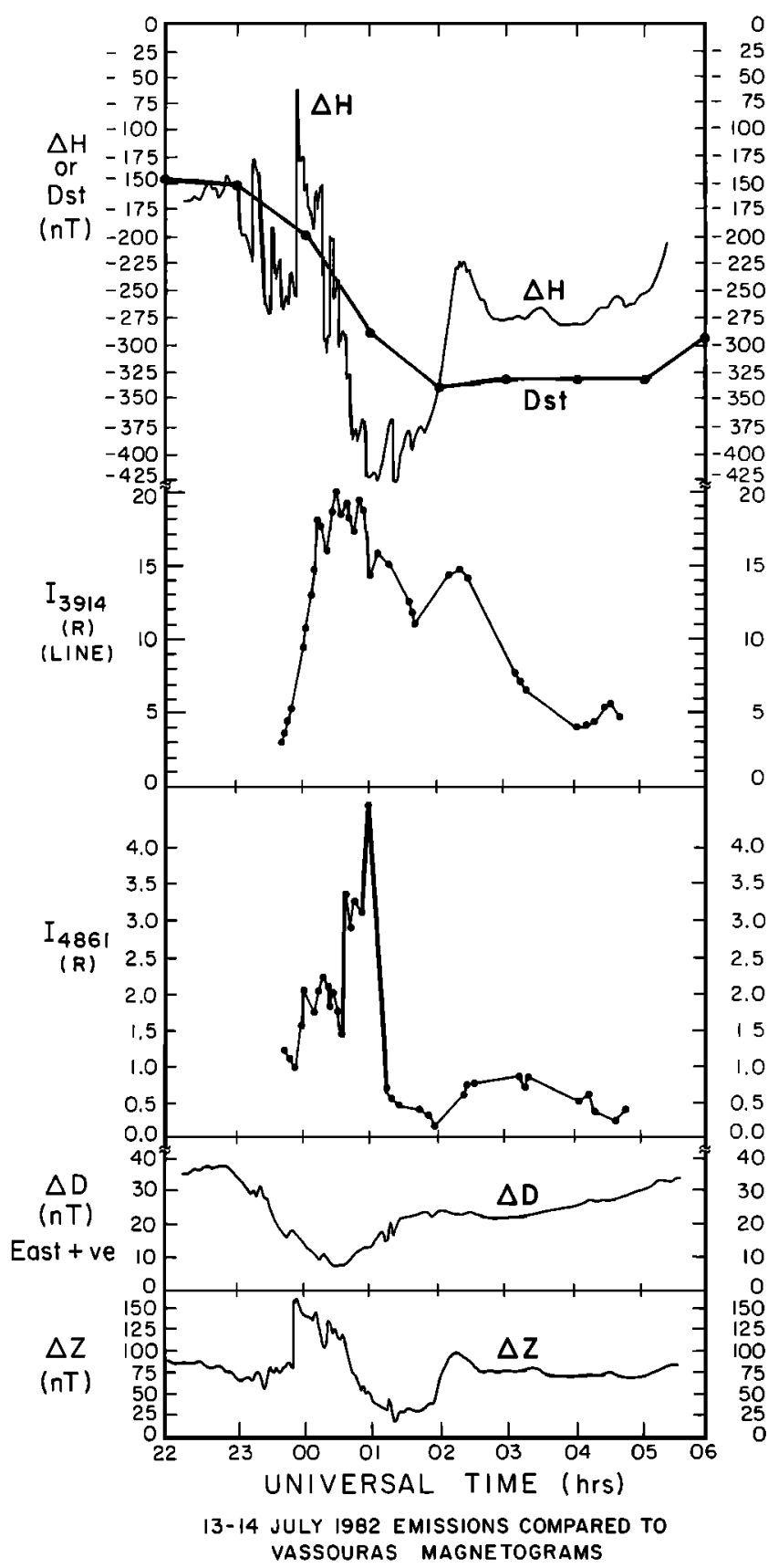

Fig. 15. Magnetograms from Vassouras, Brazil, compared to time variations of emission observed on July 13-14, 1982, from Cachoeira Paulista, Brazil.

present figures and those of Rohrbaugh et al. [1983], the precipitation occurs when Dst is large but varies with a much more rapid time scale. The close correlation with relatively localized magnetic perturbations shows that the perturbations of the trapped particles (of energy represented globally by $|D s t|)$ is not global but takes place in a relatively restricted longitude range.

There is little reason to expect direct precipitation of ring current ions at sites such as Mount Haleakala and Cachoeira Paulista within $25^{\circ}$ of the dip equator ( $L$ values of $\leq 1.2$ ), since storm time ring current is very rarely observed inside about $L=2$, corresponding to the limit for direct ion precipitation noted earlier at about $40^{\circ}$ dip latitude. Hence the observed emissions can be taken as being due to energetic neutral atoms originating at several thousand kilometers altitude at mid-latitudes from the main ring current population on shells of $L$ value of about 3, as in the model of Tinsley [1979]. For the July 13-14 observations at Cachoeira Paulista there was a relatively strong $H$ Balmer $\beta$ emission of $4861 \AA$ as compared to the $\mathrm{N}_{2}{ }^{+} 1 \mathrm{~N}(0,0)$ band at $3914 \AA$. This is an indication that between 0000 and 0100 UT the flux of precipitating particles consisted largely of hydrogen atoms but that the proportion decreased between 0100 and 0400 UT. The likely candidate for the dominant constituent at that time would be oxygen atoms.

\section{Conclusions}

The brighter low-latitude aurorae are found down to about $40^{\circ}$ dip latitude, and the vibrational development of the $\mathrm{N}_{2}^{+} 1$ $\mathbf{N}$ bands indicates the excitation at least some of the time is due to precipitating $\mathrm{O}^{+}$ions with a lower limit for the mean energy of about $1 \mathrm{keV}$ at $40^{\circ}$ dip latitude, increasing to about $15 \mathrm{keV}$ at $65^{\circ}$ dip latitude. This energy increase is consistent with satellite measurement of precipitating $\mathrm{O}^{+}$. Excitation by low-energy electrons and the resonant scattering of sunlight contribute at times to the vibrational development.

Emissions from the equator through $40^{\circ}$ dip latitude are attributed to energetic neutral atom precipitation, which originate from charge exchange of ring current ions with exospheric hydrogen.

There are rapid variations of low-latitude auroral emissions on a time scale of $\sim 0.1$ hour, which are closely related to changes in substorm currents and involve strong perturbations of the trapped ion population and large fluxes of lowenergy electrons in the thermosphere. Emission occurs at the time of positive $H$ excursions, and first positive then negative $D$ excursions, as recorded on magnetograms from nearby observatories. The positive $\Delta H$ at low latitudes is accompanied by the negative $\Delta H$ of large substorms as recorded at higher latitude observatories. The appearance of precipitating particles at these unusually low latitudes may be a consequence of the rapidity of the growth and decay of the unusually large substorms involved and the lack of time for shielding currents to halt the inward penetration of the electric fields driving the ions.

Further analysis of the magnetometer and other data for these events is needed to elucidate the three-dimensional current system involved that energizes and injects into the thermosphere the particle populations that give rise to these lowlatitude displays.

Acknowledgments. This work was supported by the Atmospheric Sciences Section, NSF, under grant ATM 8404024, by the U.S. Department of Energy under contract DE-AC06-76RL0-1830, and by the Conselho National de Desenvolvimento Cientifico e Technologico (CNPq). We wish to acknowledge the NOAA Space Environment Lab for providing magnetic storm forecasts; the Observatorio Nacional for providing Vassouras magnetometer data; and the World Data Center A, the U.S. Department of the Interior Geological Survey, and the Air Force Geophysics Lab for providing magnetometer data from all the other observatories. We thank J. S. Schumaker for assistance with generating the synthetic spectra.

The Editor thanks R. E. Daniell and J. W. Meriwether for their assistance in evaluating this paper.

\section{REFERENCES}

Ahn, B.-H., Y. Kamide, and S.-I. Akasofu, Global ionospheric current distributions during substorms, J. Geophys. Res., 89, 1613, 1984.

Akasofu, S.-I., and S. Chapman, Solar Terrestrial Physics, Oxford University Press, New York, 1972.

Barbier, D., Le spectre des aurores de basses latitudes, Ann. Geophys., 3, 117, 1947 . 
Barbier, D., Rapport sur les aurores des basses latitudes, in Relations Entre les Phénomènes Solaires et Géophysiques (Editions de la Revue d'Optique), pp. 182-192, Centre National de la Recherche Scientifique, Paris, 1949.

Bates, D. R., The intensity distribution in the nitrogen band systems emitted from the earth's upper atmosphere, Proc. $R$. Soc. London, Ser. A, 196, 217, 1949.

Belon, A. E., and K. C. Clark, Spectroscopic observations of the great aurora of Feb. 10, 1958, II, Unusual atomic leatures, J. Atmos. Terr. Phys., 16, 220, 1959.

Birely, J. H., Formation of $\mathrm{N}_{2}{ }^{+} \mathrm{B}^{2} \Sigma_{u}{ }^{+}$and $\mathrm{N}_{2} \mathrm{C}^{3} \Pi_{u}$ in collisions of $\mathrm{H}^{+}$and $\mathrm{H}$ with $\mathrm{N}_{2}$, Phys. Rev., A10, 550, 1974.

Broadfoot, A. L., Resonance scattering by $\mathrm{N}_{2}{ }^{+}$, Planet. Space Sci., 15 , $1801,1967$.

Broadfoot, A. L., and D. M. Hunten, $\mathrm{N}_{2}{ }^{+}$emission in the twilight, Planet. Space Sci., /4, 1303, 1966.

Burnside, R. G., J. W. Meriwether, Jr., and J. C. G. Walker, Airglow observations of the OI $7774 \AA$ multiplet at Arecibo during a magnetic storm, J. Geophys. Res., 85, 767, 1980

Carleton, M. P., Excitation of nitrogen by protons of a few keV energy, Phys. Rev., 107, 110, 1957.

Chamberlain, J. W., Physics of the Aurora and Airglow, p. 104, Academic, Orlando, Fla., 1961.

Chamberlain, M. T., and F. Jacka, Optical evidence for mid-latitude charged particle precipitation, J. Atmos. Terr. Phys., 4l, 111, 1979.

Chapman, S., The aurora in middle and low latitudes, Nature, 179, 7 , $1957 a$.

Chapman, S., Aurora in middle and low latitudes, Ann. Int. Geophys. Year, 4(II), 25, $1957 b$.

Clark, K. C., and A. E. Belon, Spectroscopic observations of the great aurora of Feb. 10, 1958, I, Abnormal vibration of $\mathrm{N}_{2}{ }^{+}, J$. Atmos Terr. Phys., 16, 205, 1959.

Dalgarno, A., and M. B. McElroy, Twilight effects of solar ionizing radiation, Planet. Space Sci., 14, 1321, 1966.

Degen, $\mathbf{V}$., Vibrational enhancement and the excitation of $\mathrm{N}_{2}{ }^{+}$and the first negative system in the high altitude red aurora and the dayside cusp, J. Geophys. Res., 86, 11,372, 1981.

Dufay, J., Le spectre d'une aurore de basse latitude dans le visible et le proche infrarouge, C. R. Hebd. Seances Acad. Sci., 245, 1648, 1957.

Dufay, J., and J. Gauzit, Spectre de l'aurore du 25 janvier 1938, Compt. Rend. 206, 619, 1938.

Dufay, J., and G. Moreau, Spectre de l'aurore du 21 janvier 1957, Ann. Geophys., 13, 153, 1957.

Dufay, J., and M.-L. Tcheng, Spectre de l'aurore du 18 septembre 1941, Cah. Phys., 2, 8, 1942.

Dufay, J., J. Gauzit, and M.-L. Tcheng, Spectre de L'aurore du ler mars 1941, Cah. Phys., I, I-59, 1941.

Duncan, R. A., Polarization of the red oxygen auroral line, Planet. Space. Sci., l, 112, 1959.

Fan, C. Y., Emission spectra excited by electronic and ionic impact, Phys. Rev., 103, 1740, 1956.

Fishkova, L. M., and G. V. Markova, Electrophotometric observations of low latitude aurora on 11-12 Feb. 1958 in Abastamani (in Russian), Astron. Tsirk., 191, 28, 1958.

Gotz, F. W. P., Spektren des Nordlichtes vom 25. Januar 1938 , Helvet. Phys. Acta, $11,556,1938$.

Gotz, F. W P., Eine neue Strahlung im Nordlicht des 18/19 September 1941, Naturwissenschaften, 29, 690, 1941.

Gotz, F. W. P.. Zum Nordlichtspecktrum des 17 April 1947, Experientta, 3, 185, 1947

Gotz, F. W. P., and W. Brunner-Hogger, Das Nordlicht vom 29/30 Marz 1940, Sterne Leipzig, 20, 113, 1940.

Gotz, F. W. P., and F. Schmid, Hohenmessung des Nordlichts vom 18 September 1941, Verh. Schweiz. Naturforsch. Ges., 122, 88, 1942.

Hikosaka, T., On the great enhancement of the line [OI]6300 in the aurora at Niigata on February 11, 1958, Rep. Ionos. Res. Jpn., 12, $469,1958$.

Hirao, K., N. Wakai, K. Sawada, T. Hikosaka, K. Yano, and K. Maeda, Some evidences of the particle effects on the ionosphere at middle latıtudes, Space Res., 5, 1058, 1965.

Huruhata, M., Aurora and airglow observations of Feb. 11, 1958, Rep. Ionos. Res. Jpn., 12, 40, 1958.

Ishimoto, M., M. R. Torr, P. G. Richards, and D. G. Torr, The role of energetic $\mathrm{O}^{+}$precipitation in a mid-latitude aurora, $J$. Geophys. Res., 91, 5793, 1986.

Kamide, Y., and S. Matsushita, Penetration of high-latitude electric fields into low latitudes, J. Atmos. Terr. Phys., 43, 411, 1981.
Kozyra, J. U., T. E. Cravens, A. F. Nagy, M. O. Chandler, L. H. Brace, N. C. Maynard, D. W. Slater, B. A. Emery, and S. D. Shawhan, Characteristics of a stable auroral red arc event, Geophys. Res. Lett., 9, 973, 1982

Levasseur, A.-C., and J. E. Blamont, Satellite observations of strong Balmer atmospheric emissions around the magnetic equator, $J$ Geophys. Res., 78, 3881, 1973.

Little, C. G., and H. Leinbach, Some measurements of high latitude ionospheric absorption using extraterrestrial radio waves, Proc. Inst. Radio Eng. Aust., 46, 334, 1958.

Loomis, E., The great auroral exhibition of August 28 to Sept. 4, 1859 1, Am. J. Sci., 2nd Ser., 28, 385, 1859.

Loomis, E., The great auroral exhibition of August 28 to Sept. 4, 1859 8, Am. J. Scl., 2nd Ser., 32, 318, 1861.

Manrung, E. R., and H. B. Pettit, Photometric observations of the 5577 and 6300 emissions made during the aurora of February 10-11, 1958, J. Geophys. Res., 64, 149, 1959.

Meier, R. R., and C. S. Weller, Observations of equatorial EUV bands: Evidence for low-latitude precipitation of ring current helium, J. Geophys. Res., 80, 2813, 1975.

Meriwether, J. W., and J. C. G. Walker, First negative band system of nitrogen in the night sky over Arecibo during geomagnetic storms, J. Geophys. Res., 85, 1279, 1980.

Moore, J. H., and J. P. Doering, Vibrational excitation in ionmolecule collisions: $\mathbf{H}^{+}, \mathbf{H}_{2}{ }^{+}, \mathrm{He}^{+}, \mathrm{Ne}^{+}$and electrons on $\mathbf{N}_{2}$, Phys. Rev., 177, 218, 1969a.

Moore, J. H., and J. P. Doering, Rotational excitation in ion-molecule collisions, II, $\mathrm{H}^{+}, \mathrm{D}^{+}, \mathrm{He}^{+}, \mathrm{Ne}^{+}, \mathrm{H}_{2}^{+}$and $\mathrm{D}_{2}{ }^{+}$on $\mathrm{N}_{2}^{+}$, Phys. Rev., 182, 176, $1969 b$.

Paresce, F., EUV observations of the equatorial aurora, J. Geophys. Res., 84, 4409, 1979.

Rayleigh, Lord (Strutt, R. J.), A photographic spectrum of the aurora of May 13-15, 1921 and laboratory studies in connection with it, Proc. R. Soc. London, Ser. A, IOI, 114, 1922.

Rees, M. H., and R. G. Roble, Observations and theory of the formation of stable auroral red arcs, Rev. Geophys., 13, 201, 1975.

Rohrbaugh, R. P., B. A. Tinsley, H. Rassoul, Y. Sahai, N. R. Teixeira, R. G. Tull, D. R. Doss, A. L. Cochran, W. D. Cochran, and E. S. Barker, Observations of optical emission from precipitation of energetic neutral atoms and ions from the ring current, J. Geophys. Res., $88,6317,1983$.

Seaton, M. J., Exitation processes in the aurora and airglow, 3, Low latitude aurorae, in The Airglow and the Aurora, edited by E. B. Armstrong and A. Dalgarno, p. 225, Pergamon, New York, 1956.

Sharp, R. D., R. G. Johnson, and E. G. Shelley, The morphology of energetic $\mathrm{O}^{+}$ions during two magnetic storms: Temporal variations, J. Geophys. Res., 8I, 3283, 1976 a.

Sharp, R. D., R. G. Johnson, and E. G. Shelley, The morphology of energetic $\mathrm{O}^{+}$ions during two magnetic storms: Latitudinal variations, J. Geophys. Res., 8I, 3292, 1976 b.

Shepherd, G. G., L. L. Cogger, and J. R. Burrows, Mid-latitude auroras and SAR arcs observed from the ISIS 2 spacecraft during the August 1972 geomagnetic storm, J. Geophys. Res., 81, 4597, 1976.

Sivjee, G. G., Anomalous vibrational distribution of $\mathrm{N}_{2}^{+} 1 \mathrm{~N} \mathrm{G}$ emissions from a proton aurora, J. Geophys. Res., 85, 206, 1980.

Slipher, V. M., Spectrographic studies of the planets, Mon. Not. R. Astron. Soc., 93, 657, 1933.

Slipher, V. M., and L. A. Sommer, Zur Deutung des Nordlichtspektrums, Naturwissenschaften, $17,802,1929$

Tinsley, B. A., Studies of upper atmosphere emissions, Ph.D. thesis, Univ. of Canterbury, New Zealand, 1963.

Tinsley, B. A., Measurements of twilight helium 10,830 emission, Planet. Space Sci., 16, 91, 1968.

Tinsley, B. A., Energetic neutral atom precipitation during magnetic storms: Optical emission, ionization, and energy deposition at low and middle latitudes, J. Geophys. Res., 84, 1855, 1979.

Tinsley, B. A., Neutral atom precipitation-A review, Planet. Space Sci., 43, 617, 1981.

Tinsley, B. A., and S.-I. Akasolu, A note on the lifetime of ring current particles, Planet. Space Sci., 30, 733, 1982.

Tinsley, B. A., and R. G. Burnside, Precipitation of energetic neutral hydrogen atoms at Arecibo during a magnetic storm, Geophys. Res. Lett., 8, 87, 1981.

Tinsley, B. A., R. P. Rohrbaugh, Y. Sahai, and N. R. Teixeira, Energetic oxygen precipitation as a source of vibrationally excited $\mathrm{N}_{2}{ }^{+}$ $1 \mathrm{~N}$ emissions observed at low latitudes, Geophys. Res. Lett., 9, 543, 1982.

Tinsley, B. A., R. P. Rohrbaugh, H. Rassoul, E. S. Barker, A. L. 
Cochran, W. D. Cochran, B. J. Wills, D. W. Wills, and D. Slater, Spectral characteristics of two types of low latitude aurorae, Geophys. Res. Lett., 11, 572, 1984.

Torr, M. R., and D. G. Torr, Energetic oxygen, a direct coupling mechanism between the magnetosphere and thermosphere, Geophys. Res. Lett., 6, 700, 1979.

Torr, M. R., and D. G. Torr, Energetic oxygen in a mid-latitude aurora, J. Geophys. Res., 89, 5547, 1984.

Torr, M. R., J. C. G. Walker, and D. G. Torr, Escape of fast oxygen from the atmosphere during geomagnetic storms, J. Geophys. Res., $79,5269,1974$.

U. S. Geological Survey, Magnetic dip, Epoch 1975, Map 30, Washington, D. C., 1975.

Vallance Jones, A., An analysis of a spectrogram of the red aurora of Feb. $10-11,1958$, in the wavelength range $7300-8700 \AA$, Can. J. Phys., 38, 453, 1960.

Vallance Jones, A., and D. M. Hunten, Rotational and vibrational intensity distribution of the first negative $\mathrm{N}_{2}{ }^{+}$bands in sunlit aurora, Can. J. Phys., 38, 458, 1960.

Van Zyl, B., M. W. Gealy, and H. Neumann, $\mathrm{N}_{2}{ }^{+}$first-negative emis- sion cross sections for low-energy $\mathrm{H}^{+}$and $\mathrm{H}$ impact on $\mathrm{N}_{2}$, Phys Rev. $A, 28,2141,1983$.

Van Zyl, B., M. W. Gealy, and H. Neumann, Prediction of photon yields for proton aurorae in an $\mathrm{N}_{2}$ atmosphere, J. Geophys. Res. $89,1701,1984$

Warwick, J. W., Absorption of cosmic radio noise during the great aurora of 11 February 1958, Science, 127, 1047, 1958.

Williams, D. J., Ring current composition and sources: An update, Planet. Space Sci., 29, 1195, 1981

H. Rassoul, R. Rohrbaugh, and B. A. Tinsley, Center for Space Sciences, The University of Texas at Dallas, Box 830688, Richardson, TX 75083.

Y. Sahai and N. R. Teixeira, Instituto de Pesquisas Espaciais, Sao Jose des Campos, Sao Paulo, Brazil.

D. Slater, Battelle Pacific Northwest Laboratory, Richland, WA 99352.

(Received March 18, 1986; revised May 8, 1986; accepted May 12, 1986.) 